\title{
Escritura árabe ornamental y epigrafía andalusí
}

\author{
Ma Antonia Martínez Núñez *
}

Toda escritura es la codificación de una cadena hablada con la función primordial de ser descodificada mediante la lectura, aunque ésta haya sido privilegio de minorías en determinados casos y momentos..

La escritura árabe, al igual que otras grafías semíticas, proviene de la escritura fenicia, designada más propiamente en nuestros días como escritura siro-palestina o cananea (FEVRIER, 1948; SOURDEL, 1966).

La primera etapa de la escritura árabe se inició en las llanuras siro-mesopotámicas con el empleo por grupos árabes nómadas, en el siglo VI J.C., de unos signos gráficos tomados, según unos, de los trazos cursivos de la escritura nabatea y, según otros, del siríaco tal y como se escribía en la capital lajmí (SOURDEL, 1966; SOURDEL, 197I: p. 257).

Al igual que otras grafías semíticas, definidas como "escrituras consonánticas" o "escrituras abstractas" (COHEN, 1958; FEVRIER, 1963), el sistema gráfico árabe era bastante defectivo: sólo poseía grafemas para anotar los fonemas consonánticos y las vocales largas, sin que hubiese anotación en principio para las vocales breves, y, por otra parte, los grafemas consonánticos tenían un carácter polifónico, es decir, un sólo grafema representaba varios fonemas. Este hecho suponía una gran economía a la hora de la codificación o anotación gráfica, pero un coste muy elevado para la lectura o descodificación.
En esa etapa primitiva, y como afirma J. Sourdel, nada diferenciaba a la escritura árabe de las grafías semíticas precedentes y nada permitía prever el brillante destino que tenía asignado (SOURDEL, 197I: p. 257).

$Y$ es que el primer rasgo característico que se percibe en los paises árabo-islámicos, o en los islámicos, es el lugar excepcional que ocupa en ellos el signo gráfico (MESSIK, 1993), siendo más sorprendente aún el uso abundante de la escritura árabe como elemento ornamental.

Sin duda, la razón hay que buscarla en la excelencia que el pensamiento filosófico del Islam ha otorgado a la escritura que anotaba la lengua de la revelación y que servía de vehículo a la religión. Como instrumento de transmisión de un mensaje identificado con la palabra divina, la escritura árabe permitió la conservación de la revelación, facilitando su estudio y memorización y de este hecho recibió una especie de "carácter sagrado".

La realidad de esta sacralización se encuentra afirmada por las fuentes textuales árabes. Son numerosas las aleyas coránicas que insisten en el carácter árabe de la revelación, en que el Corán es una revelación en lengua árabe (Q. XIII, 37; XXII, II2-II3; XXVI, 195, entre otras); revelación en forma de Libro, "escritura", copia del "Libro de Dios", donde todo está establecido desde que creó los cielos y la tierra (Q. III, 2-3; VI, 92 y I54-I 56; IX, 36; X, 37-

\footnotetext{
* Departamento de Filología Griega, Estudios Árabes y Traducción e Interpretación. Facultad de Filosofía y Letras. Universidad de Málaga.
} 
38, entre otras). Pero, aparte del Corán mismo, dicho carácter sagrado se recoge también en el hadit $\underline{\text { y }}$ en opiniones personales de diversos autores árabes (ROSENTHAL, 1961).

Por consiguiente, el primer punto a destacar es el incomparable prestigio, del que no ha dejado de gozar en el mundo islámico, una escritura árabe impulsada por el movimiento expansivo del Islam al que había sido asociada desde el origen (SOURDEL, 1978: p. 1145).

El prestigio así adquirido por la grafía árabe posibilitó el que se convirtiera en la escritura utilizada por igual en las más diversas y distantes regiones del imperio islámico. Los árabes conquistaron una serie de regiones a las que sometieron, constituyendo el imperio áraboislámico e introduciendo su ideología: el credo islámico. La conversión al Islam, de la que se obtenían ventajas fiscales y sociales, y el establecimiento del árabe como lengua de la administración del imperio con el califa omeya 'Abd al-Malik (685-705 J. C.), convirtieron al árabe no sólo en la lengua de la religión y la administración, sino en la lengua escrita por excelencia, aunque se hablaran otras lenguas. La escritura árabe pasó, de este modo, a desempeñar un papel social como signo y símbolo de que el contenido de los escritos pertenecía a la civilización musulmana (RODINSON, 1971: pp. 273-274; ETTINGHAUSEN, 1995: pp. 74-76). En este sentido, la escritura árabe no ha dejado de trascender, en tanto que expresión simbólica, las fronteras del mundo arabófono, siendo utilizada en las diferentes zonas islamizadas para anotar diversas lenguas: persa, turco, afgano, dialectos beréberes norteafricanos, lenguas del Africa Negra (haoussa, peul), literatura aljamiada de la España medieval, etc. (COHEN, 1958: pp. 184-186).

El giro decisivo en la primera historia de la escritura árabe estuvo marcado por la aparición del primitivo Estado islámico, pues desde entonces tal grafía estaría destinada a preservar el texto coránico y a asegurar el funcionamiento de una administración de gobierno en pleno crecimiento. Este cambio propició en adelante su progresiva utilización en escritos de todas clases: copias del Corán, inscripcio- nes piadosas, textos conmemorativos de diversas fundaciones, documentos administrativos, monedas, epígrafes sobre cerámica y otros materiales y objetos mobiliarios. Textos caligráficos y epigráficos que se realizaban con distintos fines: utilitarios, propagandísticos o sacralizados. El más antiguo documento administrativo, en pergamino, data del año 22/643 y la estela funeraria más antigua es del año 31/65l.

La segunda etapa de la escritura árabe se inaugura con la organización del Estado Omeya en Oriente, cuando se inicia el proceso de enriquecimiento del signo gráfico. Desde la época omeya las inscripciones se multiplican en todas las regiones del joven imperio islámico. El formulario de estas inscripciones era simple y sobrio, como demuestran varias inscripciones conmemorativas, las más antiguas, de época del califa 'Abd al-Malik (ORY, 1986: pp. 213 -214; BLAIR, 1992a: pp. 59-88; SHARON, 1966), y se convertiría en el prototipo de los de épocas posteriores, los cuales siguieron fieles a sus grandes líneas, aunque introdujeran variantes.

La grafía omeya monumental, de una alta perfección estética, obedecía a una serie de normas: casi siempre en labra incisa, los caracteres se componían de elementos geométricos simples y estaban dispuestos sobre una línea de base caracterizada por su horizontalidad rigurosa (ORY, 1986: p. 213), la cual juega un papel esencial en la escritura árabe, al igual que en la siríaca. Este papel es tal que en ciertos tipos de escritura árabe primitiva la línea de base es parte integrante de los caracteres. En torno a dicha línea se desarrollan dos zonas: la inferior, más densa, donde el efecto estético surge del simple juego de los caracteres, y la superior en la cual los vacíos dejados entre las trazas altas constituyen un espacio privilegiado para la pericia técnica de los artesanos. En época omeya esta zona superior quedó inutilizada, como se observa en las inscripciones de la Qubbat al-Ṣajra de Jerusalén (ORY, 1986: p. 214; BLAIR, 1992a).

Sin embargo, durante los dos primeros siglos de dominación 'abbāsí se produjo, no sólo el enriquecimiento de los formularios y títulos califales, sino también una evolución grá- 
fica orientada hacia la ornamentación de los caracteres. En la escritura tallada en relieve los trazos se dotan, ahora, de terminaciones lobuladas, palmetas, hojas o florones y también se empiezan a utilizar elementos vegetales y florales aislados para rellenar los vacíos existentes entre los trazos altos; evolución hacia la ornamentación que se documenta especialmente en la epigrafía funeraria de Egipto en el siglo III/IX (ORY, 1986: p. 214; SOURDEL, 1981: p. 644, Im. 183).

Este esfuerzo de ornamentación se expandió pronto, desde Egipto, por la Ifrīqiya fāțimí y el Magreb (GOLVIN, 1986: p. 218; ROY y POINSOT, 1950; ZBISS, 1977; HABIB, 1975), para afianzarse precisamente a partir de la conquista fāțimí de Egipto (358/969), y su esporádico dominio de Siria, como se detecta en las inscripciones de la mezquita al-Hakim de El Cairo (siglo IVIX) y después en el cenotafio de Fátima en Damasco (439//047).

El enriquecimiento de la grafía árabe era la mejor manera de magnificar el texto coránico y coincidió con la progresiva complejidad en la organización del imperio y con el desarrollo cultural de la sociedad árabo-islámica. Junto a las motivaciones de carácter ideológico y religioso, otras causas más prácticas incidieron en la evolución de la grafía árabe, causas que se pueden resumir en las necesidades de los medios comerciales, del gobierno y de la administración (SOURDEL, 1971: pp. 259-260; SOURDEL, 1978: pp. | | 44-| | 45). Junto a ello, y en otro orden de cosas, la generalización de la fabricación del papel a partir del siglo III/IX facilitó las manifestaciones de las artes de la escritura. El papel ofrecía un soporte más conveniente por lo pulido de su superficie, su ligereza, resistencia y bajo coste (SOURDEL, 1978: | |46).

Todo ello repercutió en las mejoras técnicas y ortográficas sucesivamente impuestas: uso de puntos diacríticos y de grafemas auxiliares para representar las vocales breves y otros rasgos fónicos, que caracterizarán a la grafía utilitaria y a la grafía cursiva ornamental posterior. Se puede afirmar que ya para el siglo VIII J.C. se había configurado el alfabeto árabe como lo conocemos hoy.
Sin embargo, en el periodo comprendido entre los siglos I-IV H. / VII-X J.C. se aprecia la unidad de la escritura árabe no utilitaria. Tanto los coranes antiguos, copiados sobre pergamino, como las inscripciones lapidarias muestran los mismos caracteres ennoblecidos, con una interpretación angulosa y una geometrización regular de los signos empleados. Es la variedad gráfica que denominamos "cúfico", la cual se caracteriza por la ausencia de todos los signos subsidiarios de anotación gráfica.

Es interesante destacar que la defectiva, pero prestigiosa, grafía cúfica no quedó reducida, por tanto, a la composición del Corán, sino que su uso se extendió a la epigrafía fundacional y funeraria, poniéndose asimismo en boga fórmulas que reproducían y parafraseaban el Corán, y expresiones de alabanza y bendición, incluso en los títulos califales. Por el prestigio derivado de ser la grafía de los primeros ejemplares coránicos, el cúfico se usó de manera exclusiva durante cinco siglos y en todo tipo de inscripciones: desde las más intranscendentes, que adornaban el ajuar, hasta las más fastuosas, que perpetuaban nombres de príncipes y califas en edificios religiosos y profanos.

Ahora bien, como expone J. Sourdel, una desviación tan neta en los fines asignados a la escritura -con la introducción de objetivos estéticos agregados a la función esencial de anotación de los sonidos de una lengua- no tardaría en engendrar una verdadera dualidad de la escritura árabe (SOURDEL, 197I: p. 260).

A partir del siglo $X$ J. C. se distinguen dos sistemas de grafía independientes: I) Un tipo de grafía utilitaria de notable fijeza, que se mantiene durante siglos sin apenas alteración. Es la grafía cursiva que se empieza a utilizar desde entonces en casi todas las copias coránicas, no sin ciertas reticencias. 2) Y otra eminentemente ornamental, la grafía cúfica, en la que aparecen ahora una multiplicidad de estilos como consecuencia de la configuración de diversos poderes en pugna, con sus sistemas propagandísticos, o de hábitos locales más o menos pasajeros. Esta última variedad se aprecia tanto en la caligrafía de títulos y diplomas, 
como en las inscripciones lapidarias conmemorativas y funerarias.

Así, pues, estos dos sistemas de grafía evolucionaron de forma independiente y tampoco hay que olvidar la influencia ejercida por la utilización de técnicas diferentes, dependiendo del tipo de soporte. En caligrafía ornamental surgieron estilos diversos, siempre atentos a la legibilidad, que se atribuían a la personalidad de calígrafos célebres, mencionados en relatos tradicionalmente respetados (HERBIN, I803; SADAN, 1977). En los textos monumentales se observa a partir de entonces un derroche de complicaciones formales de los trazos, complementados con profusos motivos decorativos, y todo ello en detrimento del fin primordial de la legibilidad. Se ampliaba, así, progresivamente el valor simbólico, propiciatorio y propagandístico de este sistema gráfico, destinado a lo que se puede denominar como "interpretación colectiva", más que a una lectura individualizada.

A partir del siglo XII J.C., sin embargo, las variedades de la grafía lapidaria y monumental iban a ser sustituidas por los caracteres nasjíes, los cuales, sin prescindir de diversos motivos decorativos, se mantenían más emparentados con la grafía utilitaria y su legibilidad (SOURDEL, 1986). Aunque existen precedentes sirios: inscripción de Busra de 1088 y muestras de la mezquita de Alepo de 1090 (ORY, 1986: p. 215 ; SOURDEL, 1962), desde la primera mitad del siglo XII se produjo la transformación más importante de la escritura árabe lapidaria, al ser adoptada la grafía cursiva en las inscripciones oficiales por Nūr al-Dīn, en la Siria selyuquí. En el occidente islámico tendría lugar el mismo cambio y en el mismo siglo. Desde entonces el uso de la variante cursiva se generalizó y la grafía cúfica, muy evolucionada, quedó relegada a un papel secundario.

Si ésta es, brevemente y a grandes rasgos, la evolución de la escritura árabe ornamental para todo el ámbito islámico, en al-Andalus la grafía árabe, sujeta a los grandes hitos generales mencionados, presenta, por diversos motivos, sus propios rasgos específicos, especialmente a partir de determinadas etapas cronológicas.

\section{LA EPIGRAFÍA ANDALUSí}

La conquista árabe del año 92/7 I I supuso el inicio y la implantación de la escritura árabe en la península Ibérica. El testimonio andalusí más antiguo que se posee es el proporcionado por los dinares bilingües, en grafía cúfica, acuñados por el gobernador Hurr ibn 'Abd al-Rahmān al-Taqāfi (CODERA, 1879 : pp. 53-56; VIVES, 1893: n 9-13; MEDINA, 1992: pp. 68-70).

A partir de ese momento está confirmada la continuidad ininterrumpida en el uso de la grafía cúfica con las acuñaciones que hicieron los gobernadores y emires sucesivos (OCAÑA, 1986a: p. 216). Dicha continuidad se verá plenamente corroborada a partir del emir omeya 'Abd al-Raḥmān II (822-852 J.C.), cuando la grafía cúfica comienza a aparecer ya en textos fundacionales y funerarios. La variedad gráfica cúfica será usada de manera exclusiva hasta la llegada de los almohades a la Península en el año 542// |47, momento en el que, aunque existan ciertos precedentes, se introduce la grafía cursiva como escritura ornamental oficial. Del siglo XII data también el mayor número de ejemplares de grafía ornamental no lapidaria, especialmente copias del Corán.

Para el amplio ámbito epigráfico se pueden establecer tres grandes periodos: I) desde la conquista árabe hasta la fitna (I 009- I 0 I 3) y posterior caída del califato de Córdoba, 2) periodo de los reinos de taifas y almorávides y 3 ) desde la conquista almohade hasta la liquidación del dominio islámico en la Península.

\section{Primer periodo: hasta la caída del Califato}

El primer periodo se caracteriza por el predominio absoluto del cúfico y por una gran uniformidad en su diseño, derivada de la tímida unidad política instaurada por los gobernadores y acrecentada posteriormente bajo el dominio de los Banū Umaya desde su capital Córdoba (OCAÑA, 1986a: p. 216).

Este primer periodo presenta, no obstante, tres etapas claramente diferenciadas por lo que se refiere al diseño de las trazas cúficas (OCAÑA, 1970): una primera en la que se emplea el deno- 
minado "cúfico arcaico" o primitivo, que abarca hasta los últimos años del emir Muhammad I (852-886 J. C.); la segunda caracterizada por el llamado "cúfico florido", ' cuyo pleno desarrollo se produjo bajo el primer califa de alAndalus, 'Abd al-Raḥmān al-Nāṣir (9|2-96| J.C.); y la última etapa, donde predomina el "cúfico simple", modalidad gráfica que se inaugura con el segundo califa de Córdoba, alHakam al-Mustanșir (96 I-976 J. C.), y que pervivirá en siglos posteriores.

Cuando el cúfico penetró en al-Andalus contaba ya con sesenta años de existencia. Sin embargo, los trazos cúficos que aparecen en las inscripciones árabes más antiguas de alAndalus son los mismos que aquéllos que se empleaban durante el último decenio del primer siglo de la Hégira en todo el ámbito islámico, sin que exista ninguna novedad que permita ser considerada como característica o exclusiva de al-Andalus (OCAÑA, 1970: pp. 22-26).

El primer rasgo destacable del cúfico arcaico andalusí, ya mencionado para el primitivo cúfico oriental, es la existencia de la rígida horizontalidad en torno a la línea de base, resultado de la abundancia de ligaduras o nexos de unión entre los diversos grafemas. Este hecho se convertirá en una verdadera regla que en lo sucesivo va a regir el equilibrio arquitectónico de las variedades angulosas del árabe y asimismo de la grafía cursiva, regla sólo rota en etapas tardías de la grafía árabe.

Junto a ello, el carácter primitivo o arcaico de estas trazas cúficas se resume a grandes rasgos en la ausencia de nexos curvos por debajo de la línea de base, en la ausencia de prolongación final en el trazo I4f, que a veces se identifica con la figura habitual del 5f, y en la diferenciación en altura de los trazos $2 / 14 / 17 i$ y m. y el $12 i$ y m. ${ }^{2}$ Todas estas características, en suma, confieren un aspecto rígido y primitivo al diseño de estas inscripciones.

El ejemplar más antiguo hallado hasta el momento es el texto fundacional de la primitiva mezquita aljama de Sevilla (TORRES BALBAS, 1960; OCAÑA, 1947), obra realizada por orden del emir 'Abd al-Raḥmān II en el año 214/829 y dirigida por el qāọī de la ciudad, 'Umar ibn 'Adabbas. Se trata de una inscripción con cinco líneas de labra incisa que, a pesar de su arcaísmo, fue diseñada y realizada con bastante cuidado, como corrobora el hecho de que se consigne el nombre del artesano: 'Abd al-Barr ibn Hārūn (OCAÑA, 1970: p. 23).

Realizada también por orden del mismo emir, pero algo más tardía, es la inscripción fundacional de la Alcazaba de Mérida, fechada en el año 220/835 (LEVI-PROVENÇAL, 1931: no 39, pl. XI c), el epígrafe de un capitel realizado posiblemente para la primera ampliación de la Mezquita de Córdoba (REVILLA, 1932: p. 58; LEVI-PROVENÇAI, 1931: p. 85) y un epígrafe funerario a nombre de Marwān ibn "Isà del 233/848 (OCAÑA, 1970: p. 24). Todas ellas presentan los caracteres tallados en resalto.

Los escasos ejemplares de cúfico arcaico que se conservan presentan una gran uniformidad en su diseño y demuestran que los emires omeyas de al-Andalus se mantuvieron fieles a esta modalidad gráfica cuando ya en Oriente el Estado 'abbāsi había iniciado la transformación antes mencionada.

Todavía en los primeros años del gobierno del emir Muhammad I se mantiene el cúfico arcaico, con talla en resalto, en la inscripción de la Puerta de San Esteban de la Mezquita de Córdoba (LEVI-PROVENÇAL, 1931: nº I, pl. I a), fecha-

\footnotetext{
I He de advertir que existen diversas formas de designar los diferentes tipos de grafía cúfica, llegando a establecer algunos autores (GROHMANN, 1957: p. 183) hasta ocho denominaciones distintas, si bien es cierto que muchas de ellas han sido establecidas no en función del diseño de los propios grafemas sino en base a los elementos decorativos que sirven para rellenar huecos o que constituyen el fondo por el que discurre la inscripción. En el presente artículo se sigue la terminología establecida por Manuel Ocaña para las diferentes etapas de este periodo del cúfico hispano (OCAÑA, 1970), aunque debo advertir que el designado por Ocaña como "cúfico florido", es denominado por otros autores como "foliated Kufic" (GROHMANN, 1957: pp. 183- I84), mientras reservan la designación "floriated Kufic" al que se acompaña también de motivos florales como elementos ornamentales de relleno o de fondo

2 Se hará referencia a los grafemas cúficos mediante su equivalencia numérica, especificando las cuatro posiciones (OCAÑA, I970: pp. 14-19), pues así se recoge mejor su carácter polifónico, frente al menos defectivo de la grafía utilitaria.
} 
da en el 24I/855, en el epitafio de un omeya (239/854) procedente de Pechina (ACIEN y MAR-

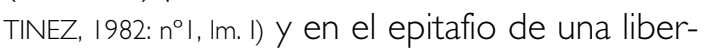
ta de al-Hakam I (LEVI-PROVENÇAL, 1931: n 2, pl. I b; OCAÑA, 1970: p. 25), con fecha del 24l/855.

A partir de entonces, el cúfico arcaico pervivirá en al-Andalus en etapas posteriores, si bien de manera esporádica y en provincias y zonas rurales, como demuestran los epígrafes arcaizantes, casi todos fechados en el siglo $X$, de Alicante, Jaén o Valencia (LEVI-PROVENÇAL, 1931: n $^{\circ}$ 95, pl. XXII b; n ${ }^{\circ}$ 91, 9, 147, 149, 151, pl. XX a y b, XXXI dy e, XXXIII, XXXIII a; LABARTA, 1990: pp. 127, 128 y n 8, 12 y 13) cuando ya en la Córdoba omeya se había producido una evidente evolución y mejora en el diseño de los epígrafes oficiales. De hecho, las zonas rurales seguirán aportando este tipo de grafía arcaica y tosca, generalmente en labra incisa, en siglos posteriores (GOULART, 1993: pp. 215217; LEVI-PROVENÇAL, 1931: n 153, 154, 156, pl. XXXIII b y c; LABARTA, 1990: $n^{\circ} 20$ ).

$Y$ es que, en efecto, desde los últimos años del emir Muhammad I comienza a efectuarse un cambio en el diseño de las trazas cúficas, cambio que se afianza con 'Abd al-Raḥmān III.

El nuevo diseño se caracteriza fundamentalmente por las formas vegetales estilizadas que adquieren las terminaciones de ciertos grafemas. Es el denominado "cúfico florido" (OCAÑA, 1970: pp. 26-35) cuya aparición en al-Andalus debe ser puesta en relación, sin duda, con la consolidación del poder omeya en la Península, la implantación definitiva del Estado y del modelo social islámicos.

La proclamación en el año $316 \mathrm{H}$. del omeya 'Abd al-Raḥmān III como califa, réplica andalusí del califato 'abbāsí y fāțimí, tuvo una amplia repercusión en todos los ámbitos (ACIEN, 1987; VALLEJO, 1992). En el terreno que nos ocupa, se observa en las inscripciones oficiales cordobesas, y especialmente en las de Madinat al-Zahrā', una actitud mimética con respecto al califato 'abbāsí. Así, por lo que se refiere a los títulos califales, junto al apelativo propiciatorio 'Abd Allāh (= siervo de Dios), de tradición omeya oriental, precediendo al ism del califa, y al título máximo de Amìr al-mu'mininn (= príncipe de los creyentes), se adopta ahora un laqab honorífico (al-Nāșir li-dīn Allāh en el caso de 'Abd alRaḥmān III) que ostentarán en adelante sus sucesores, y el título de Imām (=jefe de la comunidad), tal y como habían hecho anteriormente los califas 'abbāsíes, y frente al austero título de amir de los omeyas andalusíes precedentes (MARTINEZ, 1995b: pp. 144-146).

Por otra parte, en los epígrafes que adornaban la nueva vajilla califal de lujo -"cerámica en verde y manganeso" (CANO, 1996), que se distribuía desde Córdoba a las diferentes provincias- se empieza a utilizar de forma casi exclusiva el término al-mulk (=el poder), como "expresión estricta" de la nueva legitimidad omeya (BARCELO, 1993); expresión muy usual, casi única también, en las cerámicas de fondo amarillo y blanco de la Ifrīilya aglabí y fāțimí (DAOULATLI, 1995: pp. 73-74).

En este contexto se desarrolló una variante del cúfico florido, siguiendo en este caso también las tendencias iniciadas en Oriente, aunque esta modalidad gráfica no alcanzaría nunca en al-Andalus el nivel de complicación ornamental que llegó a alcanzar por las mismas fechas en otros territorios islámicos.

Al principio, esta innovación empieza aplicándose a muy pocos grafemas, siendo el más representativo de ellos la traza I4f y a., para extenderse a continuación a todas las figuras que lo admitían. Así, entre los años 333/94445 y 342/953-54 la grafía cúfica en al-Andalus abandonó el carácter rígido y arcaizante de la etapa precedente. Junto a las estilizaciones vegetales de los trazos altos y finales, ya mencionadas, en este periodo se realiza por primera vez el trazo I $4 \mathrm{f}$ en forma de "cuello de cisne", forma que se afianzará en épocas posteriores, si bien todavía se detecta la inconstancia en su diseño, pues aparece a veces con el austero aspecto anterior. Se constata, asimismo, la realización por debajo de la caja del renglón del nexo curvo $12 \mathrm{~m}$ I $5 \mathrm{f}$ en el término Allāh, hecho que se mantuvo posteriormente, extendiéndose su uso a otros nexos de carácter semejante. $Y$ se produce la equivalencia en altura del trazo $2 i$ con el $12 i$ en la basmala, lo que también tendría una amplia repercusión posterior. 
Sin duda, y a pesar de la existencia de tendencias arcaizantes $\mathrm{o}$, por el contrario, claramente innovadoras de algunos centros productores, las nuevas directrices para el diseño del cúfico se imponían y ejecutaban, no sin ciertos altibajos, en las inscripciones oficiales realizadas en Córdoba y en las provincias, siendo pronto imitadas, con más o menos fortuna, en la epigrafía no oficial, realizada a expensas de particulares, en los distintos territorios andalusíes.

Las primeras muestras de cúfico florido que se conservan son las inscripciones funerarias cordobesas de los mausoleos de los Banū Marwān. La más antigua de ellas es el epitafio de 'Uqār, yaāriya del emir Muhammad I, del año 268/88I (OCAÑA, 1970: p. 26, Im. V), bastante arcaizante y con un tímido desarrollo floral en las terminaciones de algunos grafemas. De Almería procede un lote de cuatro inscripciones funerarias, muestra de la epigrafía particular, con una cronología algo posterior a las cordobesas (principios del siglo IV/X), y que presentan la peculiaridad de estar grabadas por ambas caras y de haber extendido los remates florales a todos los trazos altos (OCAÑA, 1964: pp. I-4, Im. I y II).

La epigrafía oficial está representada por las inscripciones fundacionales mandadas labrar por el califa 'Abd al-Raḥmān al-Nāṣir, de las que se conservan bastantes ejemplares procedentes de Córdoba y de diversas provincias. Por lo que se refiere a las provincias, la de mayor perfección técnica es la que conmemora la construcción del arsenal de Tortosa (LEVI-PROVENÇAL, 193I: n 86, pl. XIX) en el año 333/944-45. Pero también cabría citar la inscripción del arquito del claustro de la catedral de Tarragona del 349/960-6I (OCAÑA, 1970: p. 34, Im. XVII) o la que conmemora una construcción de carácter marítimo en Almería (OCAÑA, 1964: $n^{\circ} 5$, Im. III a), entre otras.
Frente a la inscripción de la Puerta de las Palmas de la Mezquita aljama de Córdoba, obra realizada en el 346/954 y que muestra errores, rasgos arcaizantes y una escasa habilidad por parte del artesano que la labró, Sa'íd ibn Ayyūb, (OCAÑA, 1986b: p. 18, nº 2), es, sin embargo, Madīnat al-Zahrā' - por su carácter emblemático de ciudad de fundación califal como nueva sede de toda la actividad oficial - la que ha proporcionado las mejores muestras de la epigrafía oficial de esta etapa.

A los restos hallados de la inscripción fundacional de la mezquita de Madīnat al-Zahrā' del año 333/944 (PAVON MALDONADO, 1966: pp. 126I27, Im. LXXXI, LXXXIII; OCAÑA, 1970: pp. 30-3I, Im. XIII, hay que añadir los epígrafes proporcionados por el mâylis de recepciones oficiales, que hoy se conoce como "Salón Rico", y sus dependencias anejas: el llamado "pabellón sur" y los baños. El reciente estudio llevado a cabo sobre dichos epígrafes (MARTINEZ, 1995b) ha aportado resultados interesantes acerca del uso, siguiendo el modelo 'abbāsí, de formularios estereotipados que tendrán una notable fijeza posterior, o sobre la adopción del título califal y la implantación y variantes simultáneas del cúfico florido, junto a la alta dirección de las obras y la compleja actividad de los artesanos citados en los rótulos y cuya labor, frente a la opinión más extendida (IIMENEZ, 1996a: pp. 19-20) ${ }^{3}$, no parece ceñirse a la mera ejecución de los epígrafes (MARTINEZ, 1995b: pp. 142-144). Este conjunto arquitectónico fue construido entre los años 342/953-54, fecha que proporciona una basa de columna, y 345/956-57, como consta en el epígrafe fundacional de la arcada de acceso al salón (OCAÑA, 1945a). En este último aparece por primera vez, junto a la titulatura califal completa, la traza I $4 \mathrm{f}$ en forma de cuello de cisne, extensión de los remates florales a varios grafemas y elementos florales exentos para rellenar los huecos dejados entre las trazas altas, todo ello en consonancia con el resto de complicados

\footnotetext{
3 Opinión emitida por Manuel Ocaña Jiménez en base a algunos epígrafes -como el de la mezquita de Ibn cAdabbas o el del arsenal de Tortosa (OCAÑA, 1970: $n^{\circ}$ | y | I)- en que se consigna la voz kataba precediendo al nombre del artesano que labró el rótulo y que hizo extensiva a otros ejemplares, salvo cuando se especificaba una función distinta ( OCAÑA, I98I). Recientemente Alfonso Jiménez ha vuelto a plantear el tema afirmando que el tercer nombre citado en los epígrafes corresponde al artesano de la inscripción. Sin embargo, los últimos datos aportados por los epígrafes del salón de 'Abd al-Raḥmān III -en los que se emplea sistemáticamente, como en la mayor parte de las inscripciones conocidas, el ambiguo término camal (= obra de)- no permiten en modo alguno generalizar dicha hipótesis.
} 
motivos ornamentales vegetales y florales del salón (MARTINEZ, 1995b: pp. III-134).

Todos los elementos decorativos del salón, incluyendo las inscripciones, muestran un gran dominio de las técnicas de talla por parte de los diversos artesanos que los realizaron, cuyos nombres figuran en los epígrafes, estando, sin duda, adscritos a la Dār al-șināca califal de Madīnat al-Zahrā'. De estos mismos talleres -y curiosamente de manos de los mismos "artesanos" del salón, según consta en muchos de los epígrafes (MARTINEZ, 1995b: pp. 143-144)- salieron las numerosas muestras de cerámica en verde y manganeso, como el famoso plato (OCAÑA, 1970: pp. 34-35, Im. XVIII) con la leyenda baraka (= bendición) en cúfico florido ${ }^{4}$, y las exquisitas piezas de eboraria y metalistería que el califa ordenaba hacer para personas de su ámbito familiar. En las arquetas y botes de marfil o metal los artesanos seguirían rememorando, a veces, el cúfico florido, cuando ya había caído en desuso en la epigrafía monumental.

En efecto, con la llegada al poder del segundo califa de Córdoba, al-Hakam al-Mustanșir billāh, en el año 961, se produjo un cambio drástico que afectó de forma especial a la epigrafía oficial, pronto remedada en las provincias. Este cambio frenó la tendencia hacia la excesiva ornamentación vegetal y floral del cúfico anterior. Se inauguró, así, la etapa del denominado "cúfico simple", que estuvo en vigor hasta la caída del califato y pervivió con posterioridad en algunas zonas de al-Andalus.

Diversas causas, entre las cuales se insiste en el puritanismo religioso y la severa austeridad del nuevo califa (OCAÑA, 1986a: p. 216), se han esgrimido para explicar dicha orientación de la epigrafía oficial, detectable también en la simplificación y geometrización de otros elementos ornamentales. Pero es todavía un reto para la investigación futura explicar convincentemente las causas de dicho cambio, y no sólo para el ámbito epigráfico. Sí se puede afirmar, por los últimos datos que poseemos hasta el momento, que, en Madīnat al-Zahrā' los epígrafes de la remodelación del baño anejo al salón de al-Nāșir (VALLejO, 1987: p. 145; MARTINEZ, 1995b: pp. 126-129, notas 40 y 41 ) - llevada a cabo por al-Hakam en años inmediatamente posteriores a la muerte de su padre en el 350/961 - mantienen aún un cúfico semejante al de la variante más sobria de la etapa de al-Nāṣir, mientras que ya desde el año 353/964-65 (OCAÑA, 1970: pp. 35-4I, Im. XIX-XXV; OCAÑA, 1935) y, sobre todo, tras las obras de remodelación de la Mezquita de Córdoba en 354/965, se generaliza el cúfico simple, como se detecta, por ejemplo, en el epígrafe de un capitel de Madinnat al-Zahrā', del año 362H. (OCAÑA, 194I; MARTINEZ, 1995b: p. 123, nota 31).

La nueva tendencia del cúfico andalusí - que lo diferenciaba del realizado por las mismas fechas en otras regiones del mundo islámico consistió en la supresión de todos los remates vegetales y florales que adornaban las diversas trazas, consiguiéndose de este modo un nuevo cúfico de trazos desnudos, elegante y despojado de todo ornato. Si la tendencia a la ornamentación se vio frenada, no ocurrió lo mismo con la evolución del diseño de las propias trazas, el cual siguió experimentando una progresiva mejora, especialmente con el desarrollo en vertical de las figuras y el perfecto equilibrio alcanzado mediante la diferencia en altura de las diversas trazas.

\footnotetext{
4 Aunque, como ya se ha mencionado, el tema más habitual sea al-mulk, el término baraka aparece en este caso como único motivo epigráfico central, con remates vegetales en todas las trazas y con identificación del trazo $5 f$ con el I4f en la forma de cuello de cisne de este último. Así, pues, tanto este epígrafe, como los que reproducen el termino más usual de la cerámica califal, al-mulk, están realizados en cúfico florido, en consonancia con el diseño característico y oficial de los epígrafes del califato de 'Abd al-Rāhmān alNāșir, frente a la opinión que sorprendentemente sostiene Guillermo Roselló Bordoy sobre el diseño de las trazas cúficas de época de al-Nāșir y de al-Mustanșir: "...et se manifeste à travers le coufique linéaire, archaïque, plein de rudesse, caractéristique de la période du gouvernement du premier calife de Cordoue. II se maintient jusqu'au coufique fleuri, végétal, avec sa légère grâce baroque propre au moment de splendeur sous Al-Hakam II " (ROSELLO, 1995: p. 106); aparte de ofrecer también unas fechas erróneas para el periodo califal:" 9601039". Independientemente de que el cúfico florido se pudiera mantener en algunos de los epígrafes sobre cerámica, al igual que sucede también en ciertas piezas de eboraria y metalistería de época de al-Hakam II, es incuestionable que el cúfico arcaico se abandona definitivamente en la epigrafía oficial de la etapa de 'Abd al-Rāhmān III, afianzándose el desarrollo del cúfico florido que se había iniciado tímidamente ya desde el mandato del emir Muhammad l, y que con el segundo califa se impuso un nuevo diseño: el cúfico simple, que se aplicará, con más o menos rigor, a todo tipo de soportes y especialmente en la epigrafía lapidaria y monumental.
} 
De esta etapa se han conservado numerosas inscripciones conmemorativas de fundaciones de distinto carácter, mandadas realizar por al-Hakam II en todo el territorio andalusí, junto a los excelentes trabajos de eboraria producidos en la Dār al-șināca califal (GOMEZ MORENO, 1927; FERRANDIS, 1928).

Las muestras más antiguas, naturalmente epígrafes oficiales, son cuatro inscripciones conmemorativas, todas del año 353/964-65. Tres de ellas exornan dos capiteles labrados para los aposentos reales del Alcázar de Córdoba por orden de al-Hakam, bajo la dirección de su célebre liberto, h̦āŷib, y Sayf al-dawla Ŷa'far ibn 'Abd al-Raḥmān (OCAÑA, 1940; OCAÑA, 1936-39). La cuarta es la del conocido bote de marfil de la catedral de Zamora (LEVI-PROVENÇAL, 1931: n 196; OCAÑA, 1970: pp. 35-36, Im. XX), realizado para la umm walad, madre del primogénito de al Hakam, 'Abd alRaḥmān, que murió siendo niño.

Los epígrafes de los capiteles presentan algunos errores y la identificación de la traza $14 f$ con la $5 f$, pero se detecta ya la extensión de los nexos curvos a la unión de múltiples grafemas y la diferencia en altura de trazos $2 / 14 / 17 i$ y $\mathrm{m}$. consecutivos, hecho este último premeditado, con el que se intentaba dar mayor armonía y equilibrio al conjunto, y que tendrá trascendencia posterior. La inscripción del bote de Zamora es de diseño elegante y correcta ejecución, pues no presenta ninguna igualdad anómala entre los trazos. A través de ella se percibe claramente la nueva elegancia adquirida por el cúfico mediante la idónea proporción entre la altura y el grosor de los grafemas.

Del año 355/965-66 datan las inscripciones de las arquetas de marfil del Monasterio de Fitero (LEVI-PROVENÇAL, 1931: n 197) y la del Instituto Valencia de Don Juan (LEVI-PROVENÇAL, 1931: $n^{\circ}$ 198), realizadas en los talleres de Madinat alZahrā', según consta en los epígrafes, para Wallāda, hermana de al-Hakam (OCAÑA, 1970: p. 37, Im. XXII), mientras que Lévi-Provençal, por un error de lectura, dio a entender que se realizaron para Șubḥ, madre del futuro Hišām II. En ambas se da la igualdad de los trazos $5 f$ y $14 f$ en la forma de cuello de cisne de este último y algunos grafemas presentan remates florales, características que se repetirán en otras muestras de la eboraria califal posterior.

Sin embargo, la consolidación del cúfico simple encuentra su mejor reflejo en las inscripciones que conmemoran los trabajos de ampliación de la Mezquita de Córdoba, realizados por orden de al-Hakam. La inscripción del interior del mi hrāb y las que conmemoran la colocación de dos pares de columnas de apoyo al arco de entrada al nicho (LEVI-PROVENÇAL, 1931: $n^{\circ} 10$ y II, pl. III; OCAÑA, 1970: pp. 36-37, Im. XXI), ambas del 354/965, presentan los rasgos más característicos del cúfico simple de época de alHakam: multiplicación de nexos curvos por debajo de la caja del renglón para conseguir nuevos efectos decorativos, arbitrariedad en la altura de trazos $2 / / 4 / 17 i$ y $\mathrm{m}$. consecutivos, inconstancia en el diseño de la figura $14 f$, absoluta sobriedad de los signos, carencia casi total de errores de segmentación como consecuencia del planteamiento previo del texto y, en suma, preocupación por el efecto estético de todo el conjunto, a costa de sacrificar su legibilidad.

Un buen compendio de dichas características lo constituye una inscripción conmemorativa cordobesa, en la que no se consigna el objeto de la fundación, fechada en el año 358/968-69 (LEVI-PROVENÇAL, 1931: n I4, pl. V; OCAÑA, 1986b: $n^{\circ} 7$ ). Y, sin duda, las conocidas inscripciones en mosaico bizantino que dan acceso al mit?rāb de la Mezquita de Córdoba, datadas en el 354/965 aunque no se consigna la fecha (LEVIPROVENÇAL, 1931 : n 12 y 13, pl. IV; STERN, 1976; OCAÑA, 1986b: $n^{\circ} 5$ y 6 ), y las de las puertas laterales del mismo, concluidas a partir del 360/970, tras la muerte de Ŷa'far (OCAÑA, 1970: pp. 40-41), son muestras emblemáticas del cúfico simple que, en este caso, presenta motivos vegetales y geométricos para rellenar los grandes vacíos producidos entre los trazos altos, igual que aparecen en algunos rótulos de Madinat al-Zahrā'.

Los restos epigráficos conservados de época del cāmirī Almanzor demuestran el estancamiento del cúfico simple, pues no se produjo ninguna innovación digna de mencionar. Más bien se detecta un escaso empleo de nexos curvos, exceso de grosor en los cuerpos de los grafemas y bastantes errores de segmentación. Así 
se observa en la célebre pila de mármol de Madīnat al-Zāhira del año 377/987-88 (AMADOR DE LOS RIOS, 1883: p. 149; LEVI-PROVENÇAL, 1931: n 216; OCAÑA, 1970: p. 42, Im. XXVII) y, en la epigrafía de fundaciones particulares, en la inscripción de ladrillo de la mezquita de Bīb Mardūn de Toledo del 390/999- 1000, hoy ermita del Cristo de la LUZ (LEVIIPROVENÇAL, I931: n 50; OCAÑA, 1949; OCAÑA, 1970: pp. 42-43, Im. XXVIII).

Sin embargo, la etapa de los dictadores 'āmiríes, que cierra este amplio primer periodo, proporcionó también una auténtica joya de la eboraria cordobesa. Se trata de la famosa arqueta de marfil de la catedral de Pamplona, procedente del monasterio de Leyre, realizada por orden del hāŷib y Sayf al-dawla 'Abd al-Malik ibn al-Manșūr, el segundo de los dictadores 'āmiríes, en el año 395/I004-5 (LEVI-PROVENÇAL, 1931: n 204; NAVASCUES, 1964; OCAÑA, 1970: pp. 43-44, Im. XXIX). El cúfico empleado en ella es de diseño simple, pero algunas trazas presentan remate floral y la figura I $4 \mathrm{f}$ se identifica a veces con la $5 f$. Los huecos entre los trazos altos se rellenan por completo con estilizaciones vegetales, precedente del fondo de ataurique sobre el que discurrirá el cúfico de etapas posteriores, y los cuerpos de los grafemas aparecen por primera vez bordeados de un listel y macizados de pequeños discos, distinguiendo el cuerpo mismo del grafema de su borde exterior. Se trataba de una sensible mejora tras el estancamiento de época de Almanzor.

Como afirma M. Ocaña, el final del primer periodo no coincide exactamente con la fecha oficial de la caída del califato (422/I03I), pues unos veinte años antes, en época de Sulaymān al-Musta'in, la fitna desoló Córdoba (OCAÑA, 1970: p. 44). La destrucción de Córdoba durante el periodo comprendido entre febrero de 1009 y mayo de 1013, por efectos de la revuelta general de la fitna, marcó el final de la hegemonía cordobesa sobre el resto de las provincias y no sólo en el terreno político.

Por lo que se refiere a la epigrafía, Córdoba dejó de marcar en adelante los patrones a seguir, perdiendo su supremacía sobre el resto de las provincias, cada una de las cuales desarrollará a partir de entonces un tipo de dise- ño gráfico distinto del de las restantes, por causas e influencias de diverso carácter.

\section{Segundo periodo: taifas y almorávides}

Empieza así lo que ya se ha denominado $2^{\circ}$ periodo de la epigrafía andalusí, que abarca la etapa de los diversos reinos de taifas y la de los almorávides, ya que la llegada de estos últimos a la Península no supuso en el terreno epigráfico ningún cambio sustancial (OCAÑA, 1983), aunque sí se detecta la evolución y mejora en el diseño del cúfico durante la etapa almorávide en algunos centros productores, como Almería y Córdoba.

Entre los diversos reinos de taifas que se configuraron tras la fitna, unos se mantuvieron dentro del más puro estilo califal, como la propia Córdoba, Almería y Sevilla, mientras que otros se distanciaron expresamente de Córdoba y de todo lo que la misma había supuesto. La explicación hay que buscarla, sin duda, en la forma en que los distintos régulos legitimaron su autoridad: bien porque su legitimidad proviniese de su vinculación con los califas omeyas, bien por ser ellos mismos aspirantes al título califal o bien por situarse al margen y en competencia con el poder andalusí anterior.

Lo cierto es que empezaron a surgir diferentes "escuelas" en el diseño de los signos cúficos, siendo especialmente destacables las de Toledo, Sevilla, Zaragoza y Almería. Cuando irrumpen los almorávides en la Península, en el año 1086, todas estas escuelas tenían ya unas características muy acusadas que, en general, no fueron alteradas por los mulattamūn de origen sahariano, aunque en otros terrenos sí introdujeron innovaciones, como la mqäbriyya, estela funeraria prismática de sección triangular (TORRES BALBAS, 1957a: pp. 148 y ss:; MARTINEZ, 1995a: pp. 42I-422, 432-433) y las denominadas "estelas de arco de herradura" (MARTINEZ, 1995a: pp. 42I, 433434).

Toledo:

Los artesanos toledanos emplearon tanto el cúfico florido como el simple de los omeyas, pero la variante florida aparece ahora recar- 
gada con un exceso de motivos vegetales. De cada una de estas variantes hay dos versiones distintas: una de tradición cordobesa y otra más propiamente toledana consistente en añadir a los trazos labrados en relieve una acanaladura central (OCAÑA, 1983: pp. 198-199).

Como ejemplos típicos se pueden citar dos inscripciones. La primera de ellas, en caracteres cúficos con profusos remates florales, la ostenta un brocal de mármol labrado para la mezquita mayor de Toledo por orden de Abū Muḥammad ibn Ismāî̀l ibn Dī I-Nūn en el año 423/ 032 (LEVI-PROVENÇAL, 193।: n 57, pl. XV a y b). Los Banū Dī I-Nūn, beréberes descendientes de Ibn Zannūn que arabizaron su nasab, fueron señores de Toledo donde adoptaron el protocolo típico del poder islámico. Así, en esta inscripción aparece no sólo la voz amara (= ordenó), que utilizarán también otros reyes de taifas, sino el laqab honorífico de al-Žăfir (=el Triunfador) y el de $\underline{d u}$ I-ri'āsatayn (=el que ostenta las dos jefaturas), como réplica del que le había otorgado el califa de Córdoba de $d \bar{u}$ I-wizāratayn (=el que ostenta los dos visiratos) ${ }^{5}$. La segunda es un epígrafe funerario uno de los típicos y numerosos cipos toledanos (DELGADO, 1987; MARTINEZ, 1995a: pp. 422, 429-432)que contiene en caracteres simples el epitafio del wazìr Abū 'Umar ibn Mūsà, fallecido en el 465//073 (LEVI-PROVENÇAL, 1931: n 68, pl, XVII e), presentando simultáneamente las dos versiones del cúfico simple: con acanaladura central y $\sin$ ella.

En ambos epígrafes se observa una gran habilidad técnica por parte de los artesanos, los cuales utilizaron en su diseño, junto a los rasgos específicos toledanos, las características del cúfico evolucionado cordobés: abundancia de pronunciados nexos curvos, figura I4f en forma de cuello de cisne y altura arbitraria en los trazos 2/14/17i y m. consecutivos.

\section{Sevilla:}

En la Sevilla de los Banū 'Abbād los artesanos se decantaron por el cúfico simple, pero, frente al patrón cordobés clásico, desarrollaron los signos en altura hasta conseguir dotarlos de una extraordinaria esbeltez (OCAÑA, 1983: p. 199).

Una de las mejores muestras del cúfico sevillano se encuentra en una lápida de mármol en la que se conmemora la reedificación del cuerpo alto del alminar de la primitiva mezquita mayor de Sevilla (LEVI-PROVENÇAL, 1931: n 31, pl. X a), hoy Colegiata de El Salvador, en uno de cuyos muros se conserva. La obra fue realizada en el año 472/l 079 por orden del monarca Abū l-Qāsim ibn Muḥammad ibn 'Abbād', quien aparece en el epígrafe con el sobrenombre honorífico por el que era más conocido, al-Mu'tamid 'alà Allāh, y con el otro laqab de al-Mu'ayyad bi-nașr Allāh (MARTINEZ, 1987). Está realizada en cúfico simple, labrado en relieve, pero la última línea, de excelente ejecución, es de labra incisa y en ella aparecen los nombres del artesano y del director de las obras. Presenta algunas figuras muy evolucionadas, como la $15 \mathrm{~m}$ y el nexo lām-alif, mientras que el trazo I4f aparece con un diseño austero, sin prolongación ascendente final.

Estos rasgos se mantienen, con alguna variante, en otras inscripciones sevillanas oficiales, como la que conmemora la erección de otro minarete por orden de l'timād, la denominada al-sayyidat al-kubrà , umm walad, madre de alRašìd Abū l-Husayn, en el año 478/I085 (LEVIPROVENÇAL, 1931: n 32, pl. Xc, MARTINEZ, 1987). Mientras que la epigrafía funeraria semioficial y

\footnotetext{
5 La dignidad de d̦ū l-wizāratayn está documentada por primera vez en al-Andalus - desde el $269 / 882$ existía ya en la administración cabbāsí - en el año 327/939, cuando el funcionario cordobés 'Abd al-Malik ibn Šuhayd fue elevado a dicho rango por al-Nāșir, lo que le confería un prestigio especial entre el resto de los wuzarä. A partir de ese momento el doble visirato, con un carácter eminentemente honorífico, se otorgaba al funcionario más distinguido del Estado que veía, así, sus poderes reforzados, pero hasta la época nazarí no se convirtió en un oficio real de la administración (MEOUAK, 1993: p. 187).

6 Esta inscripción, que conmemora la reconstrucción del alminar de la antigua mezquita de Sevilla por orden de monarca cabbādí alMuctamid, ha sido confundida por Fátima Roldán con la primitiva inscripción fundacional de dicha mezquita a nombre de cAbd al-Rahmān II y, por tanto, la fecha en el año 214 H. (ROLDAN, 1992: pp. I43-144, n 62). La posibilidad de una confusión en la fotografía que acompaña a la ficha del catálogo hay que rechazarla en este caso, pues la reproducción fotográfica corresponde a la inscripción de época taifa, así como el enunciado de la ficha:"Inscripción conmemorativa alminar", mientras que la fecha, el comentario y la bibliografía se refieren a la inscripción fundacional en cúfico arcaico.
} 
particular presenta una mayor rigidez en el diseño y la forma de cuello de cisne se extiende a otros grafemas finales, según se desprende del epitafio del año 4I / / 022 (LEVI-PROVENÇAL, 1931: $n^{\circ} 30$ bis, pl. Xl b) y del fechado en el 505/I I I I, ya en época almorávide (LEVI-PROVENÇAL, 1931: n $^{\circ}$ 33, pl. X b).

\section{Zaragoza:}

Fue, sin embargo, en Zaragoza donde se produjo un cúfico más específico y evolucionado. Como afirma M. Ocaña, este cúfico debería ser denominado $\hat{y} a$ 'farī, puesto que es conocido principalmente por las inscripciones del palacio de la Aljafería, al-ŷaffariyya (EXPOSITO et alii, 1986: pp. 29-58; MARTIN-BUENO et alii, 1987), que mandó construir el rey de taifa Abū Ŷa'far alMuqtaḍir bi-llāh ( I 046- I082), de los Banū Hūd, a mediados del siglo $\vee \mathrm{H} . / \mathrm{XI}$ J.C. (OCAÑA, 1983: pp. 199-200). En este edificio los artesanos llevaron a cabo múltiples innovaciones arquitectónicas y decorativas, en consonancia con los modelos orientales (ROBINSON, 1992: pp. 57-62; PAVON, 1994: p. 682).

Con respecto a la decoración epigráfica, se estilizaron los trazos hasta lo inverosímil, distanciándose expresamente de los modelos cordobeses mediante una enorme prolongación en vertical de los trazos altos y unas complicadas prolongaciones finales en otros. Unas veces los caracteres discurren sobre un fondo floral, que ahora tiene por primera vez entidad propia y no es un simple elemento de relleno, como se aprecia en la inscripción del mihrāa (OCAÑA, 1983: fg.. 4) y en otros restos de frisos epigráficos (EXPOSITO et alii, 1986: p. 58; MARTIN-BUENO et alii, 1987: p. 99). En otras ocasiones se entrelazan las cabezas de los grafemas con elementos geométricos (OCAÑA, 1983: fg. 5A) O son las propias trazas cúficas las que aparecen entrelazadas con los motivos geométricos (OCAÑA, 1983: fg.. 5B). En consonancia también con los modelos del cúfico oriental (BLAIR, 1992b: pp. 238, 239 y 244, no 31 y 38, fg. $48,50,51,61$ y 62), estas características - detectadas asimismo en los frisos epigráficos del castillo de Balaguer, ciudad que estuvo también bajo dominio de los Banū Hūd (KIRCHER, 1979: p. 286) suponían un adelanto con respecto a lo que sería después la profusión decorativa del cúfi- co almohade y nazarí. Otra innovación fue el material empleado, estuco, lo que liberó a los artesanos de las limitaciones técnicas que impone la dureza y fragilidad del mármol.

Almería:

En cuanto a Almería, ciudad fundada por 'Abd al-Raḥmān al-Nāṣir y principal base de la flota omeya en el Mediterráneo, estuvo íntimamente vinculada a Córdoba durante el califato. Ello explica que se mantuviera fiel al cúfico simple de tradición cordobesa desde que se constituyó como taifa, con el eslavo Jayrān. Tal vez por esta circunstancia, el cúfico almeriense evolucionó muy lentamente y "no alcanzó su diseño más meritorio hasta la época de los almorávides" (OCAÑA, 1983: pp. 200-20I), la de mayor importancia de esta plaza marítima.

Durante este periodo Almería destaca por la cantidad y calidad de los epígrafes que ha proporcionado. Se trata, frente a la escasez de inscripciones fundacionales (OCAÑA, 1988: p. 179), de un abundante lote de estelas funerarias de época almorávide, el mayor de la Península, de una calidad de materiales -el mármol blanco de Macael- y una técnica de talla sin parangón en el resto de al-Andalus. Y es que bajo los almorávides, y en contraste con la decadencia posterior originada a raíz de la conquista de la ciudad por Alfonso VII, Almería conoció un gran desarrollo comercial y artesanal. Este auge explica el que personajes de todo tipo -artesanos, comerciantes, alfaquíes, etc.- hicieran labrar para sus tumbas suntuosas laudas, bien las denominadas estelas de arco de herradura o "arco simbólico" (LEVI-PROVENÇAL, 1931: pp. XXIV-XXV) O bien las mqābriyyas, ambas formas típicas de la Almería almorávide (TORRES BALBAS, 1957b; OCAÑA, 1988: p. 179, MARTINEZ, 1995a: pp. 432-433).

Todos los ejemplares procedentes de Almería, conservados en distintos museos de España y del extranjero, han sido catalogados e inventariados por M. Ocaña en su Repertorio (OCAÑA, 1964), al cual remito. Se pueden citar, a modo de ejemplo, la mqābriyya almeriense más antigua (OCAÑA, 1964: n' 19, Im. IX a; ACIEN y MARTINEZ, 1982: $n^{\circ}$ I3, Im. XIII), fechada en el 452/I060, que se conserva en el Museo de Málaga, y, por 
su calidad, la estela de arco de herradura que contiene el epitafio de un šayj fallecido en el 527/I I 33 (OCAÑA, 1964: nº 63, Im. XVII) y que está depositada en el Instituto Valencia de Don Juan. Ambas presentan el típico cúfico simple de tradición cordobesa, desnudo, evolucionado y de gran perfección técnica, aunque en algunos ejemplares aparecen estilizaciones vegetales que sirven de fondo.

La perfección epigráfica y decorativa de las estelas almerienses explicaría el hecho constatado de que esta ciudad se convirtiera en centro exportador de sus producciones, las cuales eran adquiridas en lugares tan lejanos como Gao, en el Sudán Occidental. En efecto, en el cementerio de Gao-Sané han aparecido estelas labradas en Almería en las primeras décadas del siglo XII, pertenecientes a las tumbas de los primeros reyes Songhoys, que se convirtieron al Islam a principios de dicho siglo y mantuvieron intensas relaciones con el Magreb y al-Andalus gracias a la unificación almorávide (SAUVAGET, 1948, SAUVAGET, 1949; MORAES FARIAS, 1990).

Por lo que respecta a otros centros productores, Córdoba, la antigua capital del califato, ha aportado escasos y fragmentarios ejemplares de este periodo. A través de ellos se detecta, como es lógico, el mantenimiento de la tradición anterior, aunque con un cierto retroceso técnico en los años inmediatamente posteriores a la caída del califato (OCAÑA, 1983: pp. 201-202). Los ejemplares más destacables de este periodo son dos estelas de arco simbólico, las más antiguas halladas hasta ahora en al-Andalus : la primera, en mármol blanco, se conserva en el Museo de Málaga y contiene en cúfico simple el epitafio de una princesa almorávide, fallecida en el 496/I I 03 (ACIEN y MARTINEZ, 1982: n 14, Im. XIV). La otra, también en mármol, está epigrafiada por las dos caras y presenta el epitafio de un Sir almorávide muerto en el 5 I7/I I 23 (LEVI-PROVENÇAL, 193I: nº 27, pl. IX a y b). Hay que señalar la semejanza entre el cúfico cordobés de época almorávide y el de la taifa sevillana; semejanza que, frente al estancamiento observado durante la época de taifas, fue señalada por Manuel Ocaña (OCAÑA, 1983: p. 201) a propósito de la estela de arco de herradura, ya citada, del año 496 H., y en base también a unas yeserías de época almorávide del baño viejo del Alcázar califal (OCAÑA, 1983: pp. 201-202, fg. 7, 8 y 10). Recientemente Ana Labarta ha incidido en la ruptura que dicha similitud produjo con respecto al "patrón cordobés clásico", encuadrándola cronológicamente entre los años 1044 y 1 I23 (LABARTA, 1994). Los últimos hallazgos arqueológicos, en concreto tres estelas de época almorávide, corroboran plenamente esta tendencia que supuso una mejora y evolución del cúfico almorávide cordobés (MARTINEZ, 1996).

Esta notable mejora del cúfico almorávide se detecta en otros centros productores, como Málaga. Así se observa en los zócalos de la Alcazaba malagueña, tanto los pintados en almagra del barrio de casas (OCAÑA, 1945b; TORRES BALBAS, 1945) como los de mármol (ACIEN y MARTINEZ, 1982: pp. 8 y 10, n० 19, Im. XXI,4), realizados en cufico simple con austera decoración vegetal de relleno, frente a la profusión ornamental de los escasos restos de la etapa de taifas (ACIEN; MARTINEZ, 1982: $n^{\circ}$ II, I2, Im. XI, XII, pp. 9-10) que se han conservado. Por sus rasgos epigráficos han sido datados en la primera mitad del siglo XII, por tanto en época almorávide ${ }^{7}$, cronología que corrobora su asombroso parecido con los epígrafes de las bandas inferiores de la qubba almorávide de Marrakech, acerca de los cuales se ha señalado también su relación con el cúfico sevillano (DEVERDUN, 1957: p. 52, fg.. 77-84).

Un cúfico muy particular se producía, sin embargo, en Badajoz con un diseño gráfico muy avanzado, distribución del epígrafe en cartelas y decoración de círculos y florones de relleno, como se aprecia en un epitafio del año 539/ I I 45 (LEVI-PROVENÇAL, 193I: n 45, pl. XII a), a nombre de 'Ubayd Allāh al-Marìdī y que consigna la fecha del levantamiento general frente a los almorávides, y en otro de las mismas

7 A pesar de que en una reciente publicación ( CALERO y MARTINEZ ENAMORADO, 1995a: p. 159) han sido adjudicados a la época almohade, sin aducir motivos convincentes (MARTINEZ, 1996); cronología que los autores extienden también (CALERO y MARTINEZ ENAMORADO, 1995b: pp. 183-184) a los arrocabes almorávides (ACIEN y MARTINEZ, 1982: I5, n 30, Im. XXXIV y $X X X V$ ) de la mezquita mayor de Málaga. 
características, pero de grafía más evolucionada, fechado ya en época almohade, 556/ | |6I, cuando la primera toma de la ciudad por los cristianos (LEVI-PROVENÇAL, I93I: n 48, pl. XII c).

Para cerrar este periodo, deben ser mencionados los restos epigráficos de Murcia durante la época de Ibn Mardanǐš. A la caída de los almorávides, el qā’id Muhammad lbn Mardanīš, el Rey Lobo de las crónicas cristianas, resistió en Murcia el empuje almohade hasta I |72. Las inscripciones conservadas de la etapa mardanīší, o de la hūdí posterior, a la que me referiré más adelante, presentan una doble vertiente: un cúfico simple semejante al almeriense, como se aprecia en algunos epitafios (LEVI-PROVENÇAL, 1931: n 100, 102 y 103, pl. XXIII b, XXIV a y b), y otro de influencia y diseño almohade, muy avanzado, con un gran desarrollo en vertical de los trazos, adelantándose en este sentido al nazarí, detectable en las muestras de inscripciones decorativas y conmemorativas (NAVARRO, 1993; NAVARRO, 1995) y en algunas estelas funerarias, como la fechada en el 577/ I I 8 I (LABARTA y BARCELO, 1992).

\section{Tercer periodo: almohades y nazaríes}

Con la llegada de los almohades a la Península en el año I I 47 se inicia el tercer y último periodo de la epigrafía andalusí, caracterizada por la evolución y fosilización del cúfico y la utilización del nasjí como grafía oficial.

Y es que el dominio almohade supuso el cambio más sustancial en el terreno epigráfico. En cuanto al uso de la variante cursiva, y por los datos que poseemos hasta el momento, la etapa almohade marcó la implantación oficial de ese tipo de grafía, más próxima a la utilitaria y su legibilidad, así como su generalización, aunque ello no implique negar la existencia de escasos y puntuales precedentes. Se sabe que la grafía cursiva, como escritura ornamental, hizo su aparición en Oriente -una de las muestras más antiguas, los epígrafes del miḥrāb del Masjid-i Pa Manar en Zavara (Irán), data del año 1068-1069 (BLAIR, 1992b: no 5I, fg.. 92), a la que siguen las ya citadas de Siria de los años 1088 y 1090- donde se consolidó como epigrafía oficial desde la primera mitad del siglo XII. De
Ifrīquiya procede el epígrafe en cursiva más antiguo del Occidente musulmán: una estela funeraria datada en 1096 (GOLVIN, 1986: p. 218), y por esta vía oriental se difundió por el resto del Magreb.

Muestras puntuales de grafía cursiva en el Magreb de época almorávide se encuentran en la qubbat al-Barūdiyyīn de Marrakech (DEVERDUN, 1957: pp. 50-52), en la mezquita de Tlemcen y probablemente en la Qarawiyyīn de Fez (OCAÑA, 1986a: pp. 216-217; FERNANDEZ PUERTAS, 1994: p. 65I), datables todas ellas en las primeras décadas del siglo Xll. Por lo que se refiere a alAndalus, la banda caligráfica del monte Mauror en Granada (GOMEZ MORENO, 1951: p. 264, fg.. 317 ; FERNANDEZ PUERTAS, 1994: p. 653) ha sido datada en época almorávide y la inscripción coránica que ostenta un doble arco de herradura del palacio de Pinohermoso, en Játiva, ha sido considerado de tradición almorávide, si bien con una cronología de principios de siglo XIII (TORRES BALBAS, 1958). De hecho, partiendo de este último epígrafe - pero adelantando su fecha a la etapa mardanǐš - y de los aparecidos en El Castillejo de Monteagudo, en la vega de Murcia (TORRES BALBAS, 1934a; TORRES BALBAS, 1934b), se ha realizado una propuesta de designación (RUBIERA, 1987: p. 295): "estilo mardanīši", definido como "nacional" frente al almohade y "donde se mezclan los elementos andalusíes con los almorávides". Murcia proporcionó y ha seguido proporcionando numerosos restos de epígrafes, tanto en cursiva como en cúfico, de las etapas mardanǐši y sobre todo almohade y hūdi, como los del Castillejo de Monteagudo (NAVARRO y JIMENEZ, 1995a: fg. 38, 44-46), Cieza (NAVARRO y JIMENEZ, 1995b: fg.. 78-80), Larache (TORRES BALBAS, 1934a: p. 366; MANZANO y BERNAL, 1992: p. 160), y alQașr al-Șagir, actualmente Convento de Santa Clara (NAVARRO, 1995: fg.. 1 19, 124). No obstante, y antes de lanzar hipótesis, en mi opinión, aventuradas sobre un "estilo nacional" mardanīši propio del Šarq al-Andalus -considerado de tradición almorávide, pero curiosa y simultáneamente como muestra de la resistencia andalusí frente a los africanos (NAVARRO, 1993), y precursor de muchas de las innovaciones posteriores-, habría que considerar las causas de esas nuevas orientaciones: si se deben a la iniciativa de los artesanos "šarquíes", creadores 
de ese "estilo", como se ha pretendido (RUBIERA, 1987: p. 295), o si responden a una de tantas iniciativas propagandísticas oficiales que supondrían, entre otras cosas, la adopción de ciertas tendencias orientales, como se ha interpretado en relación a la cerámica (GHICHARD, 1990: p. 141; NAVARRO, 1986: p. 69; ACIEN, 1996: p. 184). Pero cabría asimismo la posibilidad -teniendo en cuenta su cronología contemporánea o incluso posterior a los almohades- de una actitud competitiva, pero también mimética con respecto a los potentes sistemas de propaganda de estos últimos.

Lo cierto es que la grafía cursiva se generalizó e impuso en al-Andalus como escritura ornamental oficial a partir de la reunificación almohade (OCAÑA, 1986a: pp. 216-217); reunificación que marcó asimismo una mayor unidad en el diseño del cúfico, por ejemplo, con los llamados "motivos-tipo" (OCAÑA, 1984; OCAÑA, 1990), de gran fijeza, que incidirían por igual en la grafía cúfica que más tarde desarrollarín los nazaríes y los meriníes a ambos lados del Estrecho.

Ya Torres Balbás había señalado que los almohades, en cuanto a la decoración arquitectónica, rompieron deliberadamente con los moldes de las etapas precedentes, establecieron una relación -más estrecha que bajo sus predecesores almorávides -entre al-Andalus y el Norte de Africa, incluyendo ahora la Ifrīqiya impregnada de influencias orientales y egipcias, y desarrollaron en la arquitectura occidental y su decoración ciertas formas originarias de Oriente (TORRES BALBAS, 1949: p. 10). Y es que la opinión defendida tradicionalmente (TERRASSE, 1932) de que a partir del siglo Xl el Occidente islámico constituyó una entidad muy diferente del mundo oriental y que ambos se dieron la espalda, debe ser matizada, ya que los lazos entre ambas partes del mundo musulmán nunca se llegaron a romper tan netamente como se ha afirmado. Por el contrario, y como exponen Dominique y Janine Sourdel, "en el periodo que se extiende del siglo XI al XIII aparecieron grandes analogías" (SOURDEL, 1981: p. 124): desde los movimientos de restauración sunní de Ifríqiya a principios del siglo XI y los posteriores de almorávides y almohades -contemporáneos de otros orientales e inspirados en ciertos aspectos de los movimientos de pensamiento islámico oriental- y la introducción desde principios del siglo XIII de las madrazas, instituciones bien conocidas en Oriente desde el siglo XI, hasta la construcción de las grandes puertas monumentales almohades de Rabat y Marrakech -sin resonancia en la Península, al menos durante la etapa almohade, pero a imitación de las que levantaron los fāțimies en El Cairo a fines del siglo XI (TORRES BALBAS, 1949: p. I I)- O el uso de las muqarnas y las nuevas orientaciones de la epigrafía oficial (GROHMANN, 1957: pp. 212-213), y no se trata sólo de la utilización de la cursiva, sino que la variante cúfica adquiere en ese periodo unas características semejantes ${ }^{8}$.

Igual se podría decir de la otra afirmación, tradicionalmente mantenida en relación con la anterior, y es la de que en estos siglos el Norte de Africa, una vez cortadas las relaciones con Oriente, recibe ahora el impulso civilizador de al-Andalus; es decir, que la influencia sólo se produce en una dirección: desde al-Andalus hacia el Magreb; y más concretamente, que son los "refinados artesanos andalusíes" los que diseñan y crean todas las orientaciones e innovaciones decorativas que se producen en ambas orillas del Mediterráneo occidental. En realidad, esta argumentación, que ha contado con muchos adeptos desde siempre ${ }^{9}$, requeriría algo más que una simple matización, lo que excede los objetivos y los límites del presente estudio, por lo que remito a algunas de las opiniones que, sobre el particular, ya se han emitido (CRESSIER, 1995: pp. 87, 94; MARTINEZ, 1995a: p. 444; ACIEN y MARTINEZ, 1995). Aunque sí estimo opor-

\footnotetext{
8 Así, por ejemplo, las bandas epigráficas del mihrāb de al-Afḍal, en la mezquita de Ibn Ṭūlūn en El Cairo, erigido en el año I094, con motivos estereotipados y decoración geométrica y floral, muy parecidas a las sirias contemporáneas (SOURDEL, I981: p. 186, n 60), o los frisos de la Madraza Haydariya de Kazwin, de los siglos XI-XII, (SOURDEL, I98I: p. 240, nº65), contienen elementos análogos a los del posterior cúfico almohade.

9 Entre ellos, Torres Balbás (1949), Gómez Moreno (1951), Ocaña Jiménez (1990) y, por citar los más recientes, un estudio sobre los modos de expresión artística del Magreb (GOLVIN, 1991), el artículo ya citado de Fernández Puertas (1994) sobre la caligrafía en al-Andalus, o los que ha publicado C. Ewert sobre arquitectura islámica (EWERT, 1992 y 1995).
} 
tuno señalar, frente a la insistencia acerca de que toda innovación y desarrollo "artístico", incluyendo el de la ornamentación epigráfica, se debía al impulso de los artesanos andalusíes, el papel que cumple la epigrafía oficial como un medio propagandístico de primer orden, diseñado y controlado directamente, al igual que ocurre con otros elementos de la decoración arquitectónica (ACIEN, 1995: pp. 185-186), por el poder constituido y no dejado al arbitrio de los artesanos.

El dominio almohade representó algo más que un cambio de dinastía, llevando a cabo una profunda reforma en varias fases, pero en todos los ámbitos, desde el religioso al institucional (LAROUI, 1975: pp. 159-183; GHICHARD, 1991: pp. 186-195). Ibn Tumart se presentó como Mahdī y ostentó el título de Imām, luego los soberanos almohades mu'minies, tal y como se observa en las monedas (PRIETO, 1915), adoptaron todos los títulos protocolarios califales: el máximo de Amìr al-mu'mininn, el apelativo propiciatorio 'Abd Allāh y el laqab honorífico, así 'Abd al Mu'min recibió el de al-Qā'im bi-amr Allāh, de fuerte raigambre ismā'îlí y fãțimi (MARTINEZ, 1995b: p. 146), y también era nombrado como Jalīfa. En función de todo lo anterior se explica la necesidad de un potente sistema propagandístico, sin duda también con diversas fases en su desarrollo, que abarcara múltiples facetas; propaganda dirigida en gran medida a contrarrestar la almorávide anterior (BARBOUR, 1966), incluyendo en dicho objetivo la destrucción, a veces parcial, de epígrafes almorávides en Tlemcen (MARÇAIS, 1903: pp. 141-142), Fez y Marrakech (DEVERDUN, 1957: p. 49, nota 3). Ese control ejercido por el poder es el que da sentido a la introducción oficial de la variante gráfica cursiva y a la complicación ornamental experimentada por el cúfico, como identificativos del poder almohade, y no el impulso de los artesanos andalusíes, aunque el intercambio de mano de obra a ambos lados del Estrecho hubo de ser intenso, como acertadamente se ha señalado (OCAÑA, 1990: p. 91).

A los cambios introducidos en el terreno epigráfico hay que añadir también la diversificación de los materiales empleados: junto a la piedra abundan ahora el yeso y la madera
(TORRES BALBAS, 1949: pp. 50-55) y empieza a utilizarse la cerámica como soporte de las inscripciones funerarias. Ambas novedades se afianzarán en la etapa nazarí posterior.

Aunque en general sean escasos los restos de la etapa almohade que han llegado hasta nosotros (TORRES BALBAS, 1949: p. 9), sí se cuenta con algunos ejemplares dignos de ser mencionados y que tipifican las nuevas orientaciones. De Córdoba, por ejemplo, procede una estela funeraria de mármol con doble arco apuntado (LEVI-PROVENÇAL, I93I: n 28, pl. IX c), fechada en el 587/I | 91 . Contiene el epitafio de un šayj almohade en caracteres cúficos avanzados y la orla en grafía cursiva, ambas con decoración floral de relleno. Tanto su grafía como sus elementos decorativos son buena muestra de las innovaciones introducidas en el periodo almohade. En Palma de Mallorca se conserva un bello ejemplar de mqābriyya con alto plinto, realizado en piedra arenisca de grano fino (LEVI-PROVENÇAL, I931: n 90, pl. XXI b). Contiene el epitafio de una mujer en grafía cúfica florida evolucionada en los lados ataludados y grafía cursiva sin puntos diacríticos en los rectos. Carece de fecha, aunque G. Roselló la situó cronológicamente en el periodo intermedio entre la dinastía almorávide de los Banū Gāniya y la dominación almohade de Mallorca o, en todo caso, en una fecha anterior a la conquista cristiana de I229 (ROSELLO, 1969: p. 27, n I5, Im. III y IV).

Aunque el cúfico dejó de gozar del uso exclusivo precedente como grafía ornamental, se siguió utilizando y fue entonces cuando experimentó su evolución más espectacular. El cúfico almohade se caracteriza por un desarrollo desmesurado en vertical de las trazas altas, complementado en la parte inferior del renglón por pronunciados y abundantes nexos curvos, y por las complicaciones ornamentales vegetales o geométricas- de los remates de algunos grafemas finales y trazas altas, así como por la utilización, a veces, de estilizaciones vegetales y florales de relleno o de fondo. Es característico también que el cuerpo de cada uno de los grafemas adquiera un diseño típico y específico, que lo diferencia del resto de las figuras y que se mantendrá prácticamente inalterable en la epigrafía posterior. 
Málaga ha aportado el ejemplar de factura más perfecta de la etapa almohade. Se trata de una mqābriyya de mármol blanco (OCAÑA, 1946a y 1946b) que contiene el epitafio de Maryām, hija de Abū Ŷa'far ibn 'Abd al-Gānī, fallecida en el 6I8/I22I (ACIEN y MARTINEZ, 1982: $0^{\circ} 22$, Im. XXVII). Está realizado en caracteres cúficos típicamente almohades por el desarrollo en vertical de los grafemas, la abundancia de pronunciados nexos curvos, los remates de los trazos altos y el fondo decorativo vegetal. También en Málaga, en unas excavaciones llevadas a cabo recientemente (FERNANDEZ GUIRADO, 1990), apareció una mqābriyya única hasta el momento en al-Andalus: realizada en cerámica vidriada en verde, enmarcada en trazos de lacería, presenta en los lados triangulares decoración vegetal y en los lados trapezoidales epígrafes en cúfico, con los característicos remates de los grafemas altos, que se reducen a las expresiones al-baraka liIlāh (= la bendición es de Dios) y al-gibța almuttașila li-lläh (= la prosperidad continua es de Dios) (MARTINEZ, 1995a: pp. 437-438, Im. III, fg. 3 y 4), hecho que, por otra parte, demuestra que en época almohade tuvo su origen una disociación en los textos funerarios: largos epitafios con ampliación de los formularios, por un lado, y simples eulogias o breves textos coránicos, por otro. Algo anterior parece ser la mqābriyya de Játiva, pues aunque carece de data, ha sido fechada a finales del siglo XII (FERNANDEZ PUERTAS, 1978). Sus trazas cúficas -que reproducen fórmulas religiosas y aleyas coránicas- representan, por su diseño, una etapa intermedia en la evolución del cúfico de este último periodo.

Se puede afirmar que el cúfico almohade contaba ya con gran parte de los rasgos que luego definirían al cúfico nazarí en al-Andalus y al meriní en el Magreb. En este sentido, es de destacar que en la etapa almohade se inició también el desarrollo geométrico -a base de cintas y complicados entrelazos -que tendrán los trazos altos de los grafemas en época posterior. Una buena muestra de ello se aprecia en la lápida de la cerca de Jerez (FERNANDEZ PUERTAS, 1978: pp. 228-23I), realizada en cúfico sobre fondo liso, pero con algunos grafemas auxiliares, como el šadda, o en la inscripción del castillo de Loja, en Granada, que reproduce, también en cúfico sobre fondo desnudo, la süra coránica CXII, sobre la unidad de Allāh, y cuyos rasgos epigráficos, en los que destaca la profusión de complicaciones ornamentales vegetales y geométricas de los trazos altos, podrían situarla cronológicamente en los últimos años del dominio almohade, aunque también podría otorgársele una fecha posterior, como se ha hecho en un "avance informativo" de reciente publicación (SANCHEZ et alii, 1995: p. 47), donde se ofrece una traducción incompleta del epígrafe.

Otro hecho de gran trascendencia en la evolución del cúfico almohade, como señaló M. Ocaña, fue la creación de "motivos tipo", como demuestran los epígrafes ornamentales de la mezquita de Tinmal en Marruecos (OCAÑA, 1984). Dicha mezquita, la primera fundada por 'Abd al-Mu'min en el 549/II54, presenta la austeridad que tantas veces se ha señalado con respecto a las construcciones religiosas almohades (TORRES BALBAS, 1949: p. I0; OCAÑNA, 1990: pp. 91-92). Sin embargo, hay que destacar dos elementos: el entrelazado geométrico que enmarca el mihraāb, reproducción (HOAG, 1976: p. 108) del empleado en el portal del caravanserai Ribat-i Malik, en Uzbekistan, construido en el año 47I/I078-79 (BLAIR, 1992b: p. 259, n 58, fg. 102), y las celosías de las cúpulas que cubren la nave de antesala al mi hräb, cuyos epígrafes reproducen frases dedicadas a Allāh, escritas en cúfico y caracterizadas por una exuberante ornamentación vegetal de fondo y por un diseño muy consolidado donde se entrelazan en dos niveles las palabras que las componen. Son los "motivos tipo" -como los designó M. Ocaña (1984)- de gran fuerza decorativa y una enorme fijeza posterior, pues fueron reproducidos por los artesanos mudéjares en los territorios andalusíes tras la conquista cristiana (TORRES BALBAS, 1949: pp. 237 y ss.), degenerándose ostensiblemente con posterioridad. Pero también se incorporaron más tarde a la ornamentación de los palacios nazaríes (TORRES BALBAS, 1949: pp. 73-190) y de las construcciones meriníes, desarrollándose, a partir de ellos, el típico cúfico geométrico posterior.

Si la profusión ornamental está limitada en las mezquitas, sobre todo en el propio mihrāăb, no ocurre lo mismo en construcciones de otro 
carácter, en los que se inicia la tendencia - que triunfará plenamente en la arquitectura civil de los nazaríes y meriníes- a enmascarar la estructura interna de los edificios con enchapados y revestidos decorativos. Como afirma Torres Balbás, los tres grandes temas del arte musulmán de Occidente: la flora (ataurique), los trazados geométricos (entrelazo), todavía pobres, pero de creciente importancia, y la epigrafía, aparecen casi siempre independientes en los edificios almohades de la segunda mitad del siglo XIl y principios del XIII, para pasar después a combinarse la decoración vegetal con la geométrica o esta última con la epigráfica (TORRES BALBAS, 1949: pp. 12-14).

Buena prueba de esta tendencia, son las puertas monumentales de Rabat y Marrakech, que aparecen ricamente decoradas, a pesar de la dificultad del soporte (piedra), y constituyen, rompiendo con el carácter utilitario de las obras militares del Islam occidental, "verdaderos arcos triunfales" levantados en honor de la dinastía (TORRES BALBAS, 1949: p. 11). Dos son las puertas almohades de Rabat destacables desde el punto de vista epigráfico: la gran puerta de la Qasbah de los Udaïa (CAlLLE, 1949: pp. 96-110), construida en 1194 por el tercer soberano almohade Abū Yūsuf Yacqub al-Manșūr, que presenta en el friso superior (CAILLE, 1949: fg. 23, 24) una sucesión de motivos tipo repetidos -semejantes a los de Tinmal, pero con acentuación ahora de los entrelazados geométricos de los grafemas altos, y separados por unas columnillas cuyas prolongaciones se entremezclan en complicadas figuras geométricas- $y$ una banda epigráfica bordeando el arco (CAILLE, 1949: fg.25), en el típico cúfico almohade sobre fondo desnudo, salvo por algunas estilizaciones vegetales entre los trazos altos; la otra es la Bāb al-Rouah (CAILLE, 1949: pp. 139-144), la mayor de la cerca almohade, fue construida en el siglo XII y conserva casi íntegra la banda epigráfica en cúfico que enmarca el panel central (CAILLE, 1949: fg.45), de las mismas características que la banda de la puerta de los Udaïa, y breves inscripciones en cursiva (CAILLE, 1949: fg. 49), entre otros motivos decorativos, diseminadas por los sillares. El mismo tipo de cúfico ${ }^{10}$ presenta la banda que enmarca la Bāb Agnaou (ALLAIN y DEVERDUN, 1957: pp. I 17-120; DEVERDUN, 1956: pp. 49-50, n 59) de Marrakech, construida también por Yacqub al-Manșūr (I | 84-1 | 199). Las puertas de los siglos siguientes son una reproducción de estas almohades, como la de la Chellah (BASSET y LEVI-PROVENÇAL, 1922) de Rabat, o están inspiradas en ellas (ACIEN Y MARTINEZ, 1995).

La decoración arquitectónica de los siglos siguientes perpetuará, ampliará y desarrollará las tendencias iniciadas durante la etapa almohade, imponiendo una mayor profusión ornamental con la combinación del lazo, el ataurique y la decoración epigráfica, como se observa en los restos post-almohades que se nos han conservado en al-Andalus y el Norte de Africa. En este sentido se puede citar el mihrāa de la mezquita de Sìdī Ben Hassan (GUICHARD, 1991: p. 177, fg. 122), de Tlemcen, construida en la segunda mitad del siglo XIII, y en la que se aprecian bandas en grafía cúfica sobre un fondo poco profuso de ataurique y otros epígrafes en cursiva sin puntos diacríticos; o en la Murcia hūdi, los restos de al-Qașr al-Sagìr que presentan, junto a la mencionada profusión decorativa, la utilización de motivos-tipo en cúfico, como el término al-yumn repetido en sentido inverso y la expresión al-gibța al-muttașila (NAVARRO, 1995: fg. 126-128), y textos coránicos en grafía cursiva (NAVARRO, 1995: fg. 131, 134), O los de la casa de Onda (NAVARRO y JIMENEZ, 1995c: fg. 154-157), cuya decoración ha sido designada también como "protonazari". La misma cronología post-almohade se le ha adjudicado a una muestra de tejido, la almohada de Sancho IV el Bravo (PARTEARROYO, 1992: p. 1 12, fg. 8), en la que se observan motivos-tipo, al-yumn y al-baraka, enfrentados simétricamente.

Más problemática parece, al menos desde el punto de vista de la decoración epigráfica y su combinación con otros elementos ornamentales, la cronología almohade que se le ha otorgado al Cuarto Real de Santo Domingo (PAVON, 1991), en Granada -si bien en este caso unas veces se adjudica a la etapa almohade

10 En todas ellas se reproducen diversas citas coránicas, precedidas de la fórmula del tacawwud. 
(PAVON, 1991: pp. 15, 23, 25) y otras a la prenazarí o a los inicios de la nazarí (PAVON. 1991: pp. 14, 20,94), cronología esta última de finales del siglo XIII que coincide con la de Gómez Moreno para el Cuarto Real, la Alcazaba de la Alhambra y otros edificios nazaríes (GOMEZ-MORENO, 1966: pp. 26-33)-, y a la mezquita de Fiñana (BARCELO y GIL, 1994), especialmente en función de la decoración de su mihrāb. Si en el caso del Cuarto Real la profusión decorativa se justifica por tratarse de una construcción de carácter no religioso (PAVON, 1991: p. 15), en el de Fiñana es más difícil conjugar la austeridad, habitualmente admitida, de las mezquitas almohades con la riqueza decorativa del propio miḥrāb (BARCELO y GIL, 1994: pp. 53- 62); decoración que, en mi opinión, estaría más en consonancia con la de la etapa post-almohade o con la plenamente nazarí, a la que correspondería también el escaso margen de error observado en la orientación de la qibla "'. Así parece desprenderse no tanto del propio diseño de las trazas cúficas y de los motivos tipo, ya fijados probablemente desde época almohade, como del profuso fondo de ataurique sobre el que discurren los epígrafes en cúfico y en cursiva y también de la forma en que se presenta el término baraka, partido y con las dos primeras sílabas enmarcadas en el interior del arco formado por la prolongación de las dos últimas, como sólo se ha documentado hasta el momento en la epigrafía nazarí.

La última etapa del dominio islámico en la Península -cuando al-Andalus se vio reducido a los territorios del llamado Reino de Granada , bajo el poder de los monarcas nazaríes, Banū Nașr, desde 1239- supuso el predominio definitivo de la grafía cursiva en los epígrafes oficiales y el repliegue del cúfico, el cual quedó relegado a la mera reproducción de citas coránicas, eulogias y fórmulas de bendición, con una función primordialmente decorativa y secundaria.

A modo de inciso, creo conveniente advertir, sin embargo, que en este último periodo se suelen distinguir, por parte de los historiadores del arte y de la arquitectura (GOMEZ-MORENO, 1966; CABANELAS, 1992), dos etapas estilísticas: una primera más sobria y apartada de lo postalmohade -que marca la excepcionalidad del reino nazarí, supeditado al feudalismo castellano, frente a la pervivencia de la arquitectura y decoración postalmohade, no sólo en el Marruecos meriní, sino también en el propio al-Andalus, en la Murcia de los hūdíes (ACIEN y MARTINEZ, 1995)- y una segunda, desde mediados del siglo XIV, totalmente distinta, caracterizada fundamentalmente por los famosos palacios de Yūsuf I y Muhammad V en la Alhambra. Dicho cambio, que abarcó múltiples aspectos, entre ellos el de la decoración arquitectónica, ha sido definido como una "reislamización" del reino nazarí (ACIEN, 1984: p. 52), debida en buena parte a la influencia meriní; influencia especialmente destacable, aparte de los mencionados palacios de la Alhambra, en el caso de Ronda (ACIEN y MARTINEZ, 1995), como demuestran los restos que se nos han conservado de la decoración en yeso del miḥrāb de su mezquita, los cuales permitieron a Torres Balbás datarlo en la etapa del dominio meriní de dicha ciudad (TORRES BALBAS, 1944: p. 468), así como otros fragmentos decorativos de la misma procedencia y cronología (ACIEN y MARTINEZ, I982: n 39, 4I, 42, 44-47, Im. XLIII, $X L V, X L V I, X L V I I I-L I V)$.

Por lo que se refiere ya a la epigrafía oficial nazarí, magistralmente representada en las inscripciones de la Alhambra y el Generalife de Granada (LAFUENTE, 1860; ALMAGRO, 1879; NYKL, 193639; RUBIERA, 1995), muestra la evolución y la gran perfección alcanzadas en el diseño tanto de las trazas cursivas como de las cúficas, debido en gran parte a la utilización del estuco y la escayola como soportes, junto a la madera y la cerámica. En ambas variantes gráficas se observa ahora la generalización de un hecho insólito que contrasta con la tradición anterior: la ruptura de la línea de base, de la rígida linealidad del renglón, por la que discurrían los caracteres. En la grafía cursiva se encabalgan a veces unas palabras sobre las restantes, apareciendo

II En el siglo XIV mantiene también Alfonso Jiménez la fecha de esta mezquita de barrio en una reciente publicación (IIMENEZ, I996b: p. 167), basándose en la "correcta orientación" de su qibla, lo que la situaría en la etapa nazarí antes que en la almohade (JIMENEZ, 1991: pp. 194, 196), y "en la relativa amplitud de la nueva propuesta de datación". 
en distintos niveles. En la grafía cúfica se fragmentan los vocablos, encabalgándose también la parte inicial de una palabra sobre el resto de la misma, muy usual en el término baraka. Se conseguía, así, un importante efecto estético, ampliado con otros recursos, como enfrentar simétricamente y en sentido opuesto el mismo motivo epigráfico tipo.

Los paneles epigráficos en cursiva se complementaban generalmente con frisos y cartelas en caracteres cúficos. En grafía cursiva se realizaron las más importantes inscripciones conmemorativas de la Alhambra (LEVI-PROVENÇAL, 1931: n० 171,pl. XXXVI), así como los numerosos fragmentos poéticos que adornaban sus muros (RUBIERA, 1970; CABANELAS Y FERNANDEZ PUERTAS, 1974 75; GARCIA GOMEZ, 1985) y los del Generalife (CABANELAS y FERNANDEZ PUERTAS, 1978). Las mismas características presentan las inscripciones en cursiva halladas en otras edificaciones nazaríes de Granada, como la madrasa (LEVI-PROVENÇAL, 1931: n 172, pl. XXXVIII-XXXVIII; CABANELAS, 1988), y de otras zonas, por ejemplo, la que se conserva en el Museo de Málaga y que conmemora la construcción de una fuente (ACIEN y MARTINEZ, 1982: n²3, Im. XXVIII).

Ya para terminar y en relación a la epigrafía funeraria nazarí, el predominio de la grafía cursiva es casi absoluto. Por otra parte, ya en estas fechas se había afianzado una disociación, iniciada bajo los almohades, en los textos funerarios. Por un lado aparecen largos epitafios, labrados en piedra, con una gran profusión de textos literarios y títulos del difunto, propios de los sultanes nazaríes, como se aprecia en las estelas de la rawda de la Alhambra (TORRES BALBAS, 1926; LAFUENTE, 1860; LEVI-PROVENÇAL, 1931: pp. 145146, n० I6I, pl. XL a), y de los personajes más relevantes del momento, como en la de un príncipe de los Banū Ašqïlūla procedente de Jaén (LEVI-PROVENÇAL, 1931: n 158, pl. XXXIV, XXXV). Por otro lado, abundan las estelas cerámicas discoidales -sobre todo en los cementerios públicos de la Málaga nazarí (TEMBOURY, 1933; FERRANDIS, 1935; ACIEN, 1978), aunque también hay ejemplares de otras procedencias (FERRANDIS, 1935; TORRES BALBAS, 1957a: pp. 156 y ss.)- cuyos epígrafes, en grafía cursiva muy evolucionada, se reducen por lo general a una simple sucesión de eulogias y frases piadosas. $Y$ asimismo las estelas tabulares y discoidales de arenisca (PAVON, 1980; MARTINEZ, 1995a: pp. 424, 442-444), muy usuales en Ronda y generalmente anepígrafas.

\section{BIBLIOGRAFÍA}

ACIEN ALMANSA, M. (1978): "Estelas cerámicas epigrafiadas de la Alcazaba de Málaga", Baetica. Estudios de Arte, Geografía e Historia. I. pp. 273-278.

ACIEN ALMANSA, M. (1984): "Reino de Granada", Historia de los pueblos de España. Tierras fronterizas (I) Andalucía. Canarias. Barcelona, pp. 47-55.

ACIEN ALMANSA, M. (1987): "Madinat al-Zahrā' en el urbanismo musulmán", Cuadernos de Madinnat al-Zahrä'.। . pp. | |-26.

ACIEN ALMANSA, M. (1995): "'"Materiales e hipótesis para una interpretación del salón de 'Abd al-Raḥmān al-Nāșir", Madinat al-Zahrā'. El Salón de 'Abd al-Raḥmān III. Córdoba, pp. 179-195.

ACIEN ALMANSA, M. (1996): "Cerámica y propaganda en época almohade", Arqueología Medieval. 4. pp. |83-191.

ACIEN ALMANSA, M.; MARTINEZ NUÑEZ, $M^{a}$ A. (1982): Catálogo de las inscripciones árabes del Museo de Málaga. Madrid.

ACIEN ALMANSA, M.; MARTINEZ NUÑEZ, $M^{a}$ A. (en prensa): "Datos arqueológicos sobre la presencia meriní en Málaga", Actes du Colloque Fès et Al Andalus. Fès, 2930 novembre 1995.

ALLAIN, Ch.; DEVERDUN, G. (1957): "Les portes anciennes de Marrakech", Hespéris. XLIV. pp. 82-126

ALMAGRO CARDENAS, A. ( 1879): Estudio sobre las inscripciones árabes de Granada con un apéndice sobre su madraza o universidad árabe. Granada.

AMADOR DE LOS RIOS, R. (I883): Museo Arqueológico Nacional. Memoria acerca de algunas inscripciones arábigas de España y Portugal. Madrid.

BARBOUR, N. (1966): "La guerra psicológica de los almohades frente a los almorávides", Boletín de la Asociación Española de Orientalistas. II. pp. | |7-| 30.

BARCELO, M. (1993): "Al-mulk, el verde y el blanco .La vajilla califal omeya de Madinat al-Zahrā'", A. Malpica (ed.): La cerámica altomedieval en el Sur de al-Andalus. Primer Encuentro de Arqueología y Patrimonio. Salobreña, 1991. Granada, pp. 29I-300.

BARCELO TORRES, C;; GIL ALBARRACIN, A. (1994): La mezquita almohade de Fiñana (Almería). Almería-Barcelona.

BASSET, H.; LEVI-PROVENÇAL, E. (1922): Chella: une necrópole merinide. París. 
BLAIR, S. ( 1992a): "What Date of the Dome of the Rock", J. Raby; J. Johns (eds.): Bayt al-Maqdis. Abd al-Malik's Jerusalem. Part One. Oxford, pp. 50-88.

BLAIR, S. (1992b): The monumental inscriptions from early Islamic Iran and Transoxiana. Leiden- Nueva York.

CABANELAS RODRIGUEZ, D.; FERNANDEZ PUERTAS, A. (1974-75): "Inscripciones poéticas del Partal y de la fachada de Comares", Cuadernos de la Alhambra. 10I।. pp. I 17-200.

CABANELAS RODRIGUEZ, D.; FERNANDEZ PUERTAS, A. (1978):"Las inscripciones poéticas del Generalife", Cuadernos de la Alhambra. I4. pp. 3-86.

CABANELAS RODRIGUEZ, D. (1988): "La madraza árabe de Granada y su suerte en época cristiana", Cuadernos de la Alhambra. 24. pp. 29-54.

CABANELAS RODRIGUEZ, D. (1992): "La Alhambra: introducción histórica", J. Dodds (ed.): Al-Andalus. Las artes islámicas en España. Madrid, pp. 127-133.

CAILLE, J. (1949): La ville de Rabat jusqu'au Protectorat français. Histoire et archèologie. Vol. I. París.

CALERO SECALL, M ${ }^{a}$ I. ; MARTINEZ ENAMORADO, V. (1995a): "Arquitectura residencial de la Málaga almohade", J. Navarro Palazón (ed.): Casas y Palacios de al-Andalus siglos XII y XIII. Barcelona, pp. I57-I64

CALERO SECALL, Mª.; MARTINEZ ENAMORADO, V. (1995b): Málaga, ciudad de al-Andalus. Málaga.

CANO PIEDRA, C. (1996): La cerámica verde y manganeso de Madinat al-Zahrä'. Granada.

CODERA Y ZAYDIN, F. (I879): Tratado de numismática arábigo-española. Madrid.

COHEN, M. (1958): La grand invention de l'écriture et son evolution. París.

CRESSIER, P. (1995): "El capitel en la arquitectura nazari", Arte islámico en Granada. Propuesta para un Museo de la Alhambra. Granada, pp. 83-95.

DAOULATLI, A. (1995): "La production vert et brun en Tunisie du IXe au Xlle siècle. Etude historique et stylistique", Le vert \& le brun de Kairouan à Avignon, céramiques du Xe au XVe siècle. Marsella, pp. 69-76.

DELGADO VALERO, C. (1987): "La columna sepulcral: una forma del arte helenístico y del arte islámico". Actas II Congreso de Arqueología Medieval Española (Madrid, 1924 enero 1987). II Comunicaciones. Madrid, pp. 559-566.

DEVERDUN, G. (1956): Inscriptions arabes de Marrakech. Rabat.

DEVERDUN, G. (1957): "Etude épigraphique", J. Meunié y H. Terrasse: Nouvelles recherches archéologiques à Marrakech. La coupole almoravide de Marrakech. París, pp. 49-53.

ETTINGHAUSEN, R. ( 1995): "Arte y arquitectura islámicos", B. Lewis (ed.): El mundo del Islam. Gente, cultura, fe. Barcelona, pp. 65-102.
EWERT, C. (1992): "La herencia artística de la España islámica en el Norte de Africa", J. Dodds (ed.): Al-Andalus. Las artes islámicas en España. Madrid, pp. 85-95.

EWERT, C. (1995): "Precedentes de la arquitectura nazarí. La arquitectura de al-Andalus y su exportación al Norte de Africa hasta el siglo XII", Arte islámico en Granada. Propuesta para un Museo de la Alhambra. Granada, pp. 55-6।.

EXPOSITO SEBASTIAN, M.; PANO GRACIA, J. L.; SEPULVEDA SAURAS, Ma I. (1986): La Aljafería de Zaragoza. Guía histórico-artística y literaria. Zaragoza.

FERNANDEZ GUIRADO, I. (en prensa): "Informe arqueológico del sondeo realizado en el solar de calle Agua n 16 (Málaga)", Anuario Arqueológico de Andalucía /1990.

FERNANDEZ PUERTAS, A. (1978-79): "Dos lápidas almohades. Mqābrìya de Játiva y lápida de la cerca de Jerez de la Frontera", Miscelánea de Estudios Arabes y Hebraicos. XXXVII-XXXVIII, I. pp. 223-232.

FERNANDEZ PUERTAS, A. (1994): "Calligraphy in alAndalus", S. Kh. Jayyusi (ed.): The Legacy of Muslim Spain. vol. II. Leiden-Nueva York-Colonia, pp. 639-676.

FERRANDIS, A. (1928): Marfiles y azabaches españoles. Barcelona, Buenos Aires.

FERRANDIS TORRES, J. (1935): " Estelas cerámicas", AlAndalus. III. pp. I79-180

FEVRIER, J. G. (1948): Histoire de l'écriture. París.

FEVRIER, J. G. (1963):"Les sémites et l'alphabet. Ecritures concrètes et écritures abstraites", L' écriture et la psycologie des peuples. París, pp. I17-129.

GARCIA GOMEZ, E. (1985): Poemas árabes en los muros y fuentes de la Alhambra. Madrid.

GOLVIN, L. (1986): "Kitābāt". IV. "Afrique du Nord", Encyclopédie de I'Islam. Nouvelle édition. V. pp. 217-219.

GOLVIN, L. (199|): "Les modes d'expression artistique au Maghreb", F. Gabrieli et alii: Maghreb Médiéval. L'apogée de la civilisation islamique dans l'Occident arabe. Aixen Provence, pp. 227-28I.

GOMEZ MORENO, M. (1927): "Los marfiles cordobeses y sus derivaciones", Archivo Español de Arte y Arqueología. 3. pp. 233-243.

GOMEZ MORENO, M. (195I): El arte español hasta los almohades. Arte mozárabe. Ars Hispaniae. III. Madrid.

GOMEZ-MORENO MARTINEZ, M. (1966): "Granada en el siglo XIII", Cuadernos de la Alhambra. 2. pp. 3-42.

GOULART DE MELO BORGES, A. (1993): "Inscriçoes árabes de Noudar", Arqueologia Medieval. 2. pp. 215-217.

GROHMANN, A. (1957): "The origins and early development of floriated Kufic", Ars Orientalis. II. pp. 183-2 I3

GUICHARD, P. (1990): Les musulmans de Valence et la Reconquete (Xle-XIlle siècles). I. Damasco. 
GUICHARD, P. (199|): "Les Etats musulmans du Maghreb", F. Gabrieli et alii: Maghreb Médiéval. L'apogée de la civilisation islamique dans I'Occident arabe. Aix-en Provence, pp. 79-226.

HABIB, M. el- (1975): "Stèles funeraires kairouanaises du Ille/IXe siècle. Etude typologique et esthétique", Revue des Etudes Islamiques. XLIII, 2. pp. 227-286.

HERBIN, A. (I 803): Essai de calligraphie orientale. París.

HOAG, J. D. (1976): Arquitectura islámica. Trad. J. Novella Domingo. Madrid.

JIMENEZ MARTIN, A. (199|): "La qibla extraviada", Cuadernos de Madinat al-Zahrä'. 3. pp. 189-202.

JIMENEZ MARTIN, A. (1996a): "¿Quién diseñó la casa de Umm Salama?", Arquitectura en al-Andalus. Documentos para el siglo XXI. Barcelona, pp. 17-25.

JIMENEZ MARTIN, A. (1996b): "Cien edificios en cuatro jornadas", Arquitectura en al-Andalus. Documentos para el siglo XXI. Barcelona, pp. 89-199.

KIRCHER, G. (1979): "Estudios epigráficos sobre fragmentos de yeserías de Balaguer", C. Ewert: Hallazgos islámicos en Balaguer y la Aljafería de Zaragoza. Madrid, pp. 277-287.

LABARTA, A. (1990): "Las lápidas árabes de la provincia de Jaén", Homenaje a Manuel Ocaña Jiménez. Córdoba pp. 123-137.

LABARTA, A. (1994): " Fragmento epigráfico cordobés de época taifa", Al-Qanțara. XV. pp. 24I-243

LABARTA, A. y BARCELO, C. (1992): " Miscelánea epigráfica", Al-Qantara. XIII, pp. 537 - 559.

LAFUENTE Y ALCANTARA, E. (1860): Inscripciones árabes de Granada, precedidas de una reseña histórica y de la genealogía detallada de los reyes Alahmares. Madrid.

LAROUI, A. (1975): L'histoire du Maghreb. Un essai de synthèse. vol. I. Paris.

LEVI-PROVENÇAL, E. (1931): Inscriptions arabes d'Espagne. Leiden-París.

MANZANO MARTINEZ, J:: BERNAL PASCUAL, F. (1992): "Un palacio fortificado musulmán en la huerta de Murcia: el castillo de Larache. Estado actual de la investigación", Verdolay. Revista del Museo de Murcia. 4. pp. I53- 66.

MARÇAIS, W. et G. (1903): Les monuments arabes de Tlemcem. París.

MARTIN-BUENO,M.; ERICE LACABE, R.; SAENZ PRECIADO, M P. P. (1987): La Aljafería. Investigación arqueológica. Zaragoza.

MARTINEZ NUÑEZ, Ma A. (1987): "Inscripción falsa a nombre de l'timād", Homenaje al Prof. Darío Cabanelas Rodríguez O.F.M. con motivo de su LXX aniversario. Granada. II. pp. 26I-269.
MARTINEZ NUÑEZ, Ma A. (1995a): " La estela funeraria en el mundo andalusi", C. de la Casa (ed.): Actas del $\checkmark$ Congreso Internacional de Estelas Funerarias (Soria 28 de abril al I de mayo, 1993). Soria, pp. 419-444.

MARTINEZ NUÑEZ, Ma A. (1995b): "La epigrafía del Salón de 'Abd al-Rahmān III", Madinat al-Zahrä'. El Salón de 'Abd al-Rahmān III. Córdoba, pp. I07-I52.

MARTINEZ NUÑEZ, Ma A. (1996): "Tres estelas funerarias de época almorávide aparecidas en Córdoba", Miscelánea de estudios Árabes y Hebraicos. 45, pp. I33-I46.

MEDINA GOMEZ, A. (1992): Monedas hispano-musulmanas.Manual de lectura y clasificación. Toledo.

MEOUAK, M. (1993): "Notes sur le vizirat et les vizirs en al-Andalus à l'époque umayyade (milieu du lle/VIlle - fin du IVe/Xe siècles)", Studia Islamica. LXXVIII. pp. | 8| - 190

MESSICK, B. (1993): The Calligraphic State. Textual Domination and History in a Muslim Society. Berkeley, Los Angeles, Oxford.

MORAES FARIAS, P. F. de, (1990): " The oldest extant writing of West Africa: Medieval epigraphs from Essuk, Saney and Egef-n-Tawaqqast (Mali)", Journal des Africanistes. 60. pp. 65-113.

NAVARRO PALAZON, J. (1986): La cerámica esgrafiada andalusí de Murcia, La céramique hispano-arabe à décor esgrafié de Murcie. Madrid.

NAVARRO PALAZON, J. ( I993): Shara al-Andalus. Resistencia frente a los almohades. (con ocasión de la Exposición, 22 de diciembre de 1993/31 de enero de 1994) Murcia.

NAVARRO PALAZON, J. (1995): "Un palacio protonazarí en la Murcia del siglo XIII: al-Qașr al-Șagîr", J. Navarro Palazón (ed.): Casas y Palacios de al-Andalus siglos XII y XIII. Barcelona, pp. 177-206.

NAVARRO PALAZON, J.: JIMENEZ CASTILLO, P (1995a): "El Castillejo de Monteagudo: Qasr Ibn Sacd", J. Navarro Palazón (ed.): Casas y Palacios de al-Andalus siglos XII y XIII. Barcelona, pp. 63- I04.

NAVARRO PALAZON, J.; JIMENEZ CASTILLO, P. (1995b): "La decoración almohade en la arquitectura doméstica: la casa n 10 de Siyāsa", J. Navarro Palazón (ed.): Casas y Palacios de al-Andalus siglos XII y XIII. Barcelona, pp. |17-|38.

NAVARRO PALAZON, J:; IIMENEZ CASTILLO, P. (1995c): "La decoración protonazarí en la arquitectura doméstica: la casa de Onda", J. Navarro Palazón (ed.): Casas y Palacios de al-Andalus siglos XII y XIII. Barcelona, pp. 207-223.

NAVASCUES Y DE PALACIO, J. de (1964): "Una escuela de eboraria, en Córdoba, de fines del s. IV de la Hégira (XI d.J.C.), o, las inscripciones de la arqueta hispano-musulmana llamada de Leyre", Al-Andalus. XXIX. pp. 199-206.

NYKL, A.R. (1936-39): "Inscripciones árabes de la Alhambra", Al-Andalus. IV. pp. 174-194. 
OCAÑA JIMENEZ, M. (1936-39): "Capiteles epigrafiados de Madinat al-Zahrā'", Al-Andalus. IV. pp. I58-165.

OCAÑA JIMENEZ, M. (1940): "Capiteles fechados en el siglo X", Al-Andalus. V. pp. 437-449.

OCAÑA JIMENEZ, M. (1945a): "Inscripciones árabes descubiertas en Madinat al-Zahrā' en 1944", Al-Andalus. X. pp. $154-159$.

OCAÑA JIMENEZ, M. (1945b): "Zócalos hispanomusulmanes del siglo XII", Al-Andalus. X, pp. I64-169.

OCAÑA JIMENEZ, M. (1946a): "Una mqābriyya almohade malagueña del año I22I J.C.", Al- Andalus. Xl. pp. 224230.

OCAÑA JIMENEZ, M. (1946b): "Nuevos datos sobre la mqābriyya almohade malagueña del año 122 I J.C.", Al-Andalus. XI. pp. 445-446.

OCAÑA JIMENEZ, M. (1947): "La inscripción fundacional de la Mezquita de Ibn 'Adabbas de Sevilla", Al-Andalus. XII. pp. |45-|5|.

OCAÑA JIMENEZ, m. (1949): "La inscripción fundacional de la mezquita de Bīb al-Mardūn en Toledo", Al-Andalus. XIV. pp. I75-I83.

OCAÑA JIMENEZ, M. (1964): Repertorio de las inscripciones árabes de Almería. Madrid, Granada.

OCAÑA JIMENEZ, M. (1970): El cúfico hispano y su evolución. Madrid.

OCAÑA JIMENEZ, M. (198I): "Arquitectos y mano de obra en la construcción de la gran mezquita de Occidente", Boletín de la Real Academia de Córdoba de Ciencias, Bellas Letras y Nobles Artes. 102. pp. 97-137

OCAÑA JIMENEZ, M. (1983): "La epigrafía hispano-árabe durante el periodo de taifas y almorávides", Actas del IV Coloquio hispano-tunecino. Palma de Mallorca, 1979. Madrid, pp. 197-204.

OCAÑA JIMENEZ, M. (1984): "Cúpulas de la mezquita de Tinmal: las inscripciones de sus celosías", C. Ewert y J. P. Wisshak, Forschunden zur almohadischen Moschee. Lieferung 2. Die Moschee von Tinmal (Marocco). Madrider Beiträge, Band 10, pp. 160-168.

OCAÑA JIMENEZ, M. (1986a). "Kitābāt". III. "Espagne", Encyclopédie de l'Islam. Nouvelle édition. V. pp. 215-217.

OCAÑA JIMENEZ, M. (1986b): "Documentos epigráficos de la Mezquita", Exposición «La Mezquita de Córdoba: siglos VIII al XV \». XII Centenario de la Mezquita de Córdoba. Córdoba, pp. 16-29.

OCAÑA JIMENEZ, M. (1988): "Historia y epigrafía en la Almería islámica", Homenaje al Padre Tapia. Almería en la Historia. I Encuentro de Cultura Mediterránea (Almería 27 al 31 de octubre 1986). Almería, pp. 173-188.

OCAÑA JIMENEZ, M. (1990): "Panorama sobre el arte almohade en España", Cuadernos de la Alhambra. 26. pp. $91-111$.
ORY, S. ( 1986): "Kitābāt". II. "Proche Orient" , Encyclopédie de l'slam. Nouvelle édition. V. pp. 213-2I5.

PARTEARROYO, C. (1992): "Tejidos almorávides y almohades", J. D. Dodds (ed.): Al-Andalus. Las artes islámicas en España. Madrid, pp. I05-II3.

PAVON MALDONADO, B. (1966): Memoria de la excavación de Madinat al-Zahra. Madrid.

PAVON MALDONADO, B. (1980): "De nuevo sobre Ronda musulmana", Awraq. III. pp. I3|-174.

PAVON MALDONADO, B. (199|): El Cuarto Real de Santo Domingo de Granada. (Los orígenes del arte nazarí). Colaboración de C. Barceló. Granada.

PAVON MALDONADO, B. (1994): "El arte", Mª J. Viguera (coord.): Los reinos de taifas. Al-Andalus en el siglo XI. vol. VIII Historia de España de R. Menéndez Pidal. Madrid, pp. $65|-7| 6$.

PRIETO Y VIVES, A. (19|5): "La reforma numismática de los almohades", Miscelánea de Estudios y Textos Arabes. Madrid, pp. | |-||4.

REVILLA VIELVA, R. (1932): Patio árabe del Museo Arqueológico Nacional. Catálogo descriptivo. Madrid.

ROBINSON, C. (1992): "Las artes en los reinos de taifas", J. D. Dodds (ed.): Al-Andalus. Las artes islámicas en España. Madrid, pp. 49-62.

RODINSON, M. (197I): "El mundo islámico y la extensión de la escritura árabe", La escritura y la psicología de

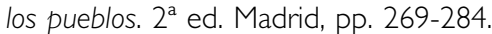

ROLDAN CASTRO, F. (1992): "Entre gentes del libro. La dominación islámica", Magna Hispalensis. Catálogo Exposición Santa Iglesia Catedral Metropolitana de Sevilla, 5 de mayo-30 de octubre de 1992. Sevilla, pp. I| 8-|44.

ROSELLO BORDOY, G. (1969): Corpus balear de epigrafia árabe. Palma de Mallorca.

ROSELLO BORDOY, G. (1995): "La céramique verte et brune en al-Andalus du Xe au XIlle siècle", Le vert \& le brun de Kairouan à Avignon, céramiques du Xe au XVe siècle. Marsella, pp. 105-109.

ROSENTHAL, F. (1961): "Significant Uses of Arabic Writing", Ars Orientalis. 4. pp. 15-23.

ROY, B.; POINSOT, P. (1950): Inscriptions arabes de Kairouan. París.

RUBIERA MATA, Ma J. (1970): " Los poemas epigráficos de lbn al-Ŷayyāb en la Alhambra", Al-Andalus. XXXV. pp. 453-473.

RUBIERA MATA, M ${ }^{\mathrm{a}}$ J. (1987): "Las inscripciones árabes de Játiva: una hipótesis y una propouesta sobre la denominación de un estilo", Homenaje al Prof. Darío Cabanelas Rodríguez, O.F.M., con motivo de su LXX aniversario. II. Granada, pp. 293-295. 
RUBIERA MATA, Mª J. (1995): "Los textos epigráficos de los palacios nazaríes", Arte islámico en Granada. Propuesta para un Museo de la Alhambra. Granada, pp. 97- 05.

SADAN, J. (1977): "Encore de nouveau sur scribes et copistes", Revue des Etudes Islamiques. XLV. pp. 4I-88.

SANCHEZ MARTINEZ, J. A.; BUENDIA MORENO, A. F.; CASTELLANO GAMEZ, M.; CUELLO SAEZ, I. M. (1995): "Reencuentro con Medina Lawsa. Un proyecto de arqueología medieval en Loja", Revista de Arqueología. I70-junio, pp. 42-47.

SAUVAGET, J. (1948): "Notes préliminaires sur les épitaphes de Gao", Revue des Etudes Islamiques. XV-XVII. pp. $5-12$.

SAUVAGET, J. (1949): "Les épitaphes royales de Gao", Al-Andalus. XIV. pp. 123-I4I.

SHARON, M. (1966): "An Arabic Inscription from the time of the Caliph "Abd al-Malik", Bulletin de la Société d'Orientalistes et Arabisants. XXIX, 2. pp. 367-372.

SOURDEL, D. y J. (198|): La civilización clásica del Islam. Trad. D. Sánchez Aleu. Barcelona.

SOURDEL-THOMINE, J. (1962): "Quelques étapes et perspectives de l'épigraphie arabe", Studia Islamica. XVII. pp. 5-22.

SOURDEL-THOMINE, J. (1966): "Les origines de l'écriture arabe. A propos d'une hipothèse récente", Revue des Etudes Islamiques. XXXIV. pp. 15।-157.

SOURDEL-THOMINE, J. (197I): "La escritura árabe y su evolución ornamental", La escritura y la psicología de los pueblos. $2^{\mathrm{a}}$ ed. Madrid, pp. 255-268.

SOURDEL-THOMINE, J. (1978): "Khatț", Encyclopédie de I'Ilam. Nouvelle édition. IV. pp. I | 44-। I 54.

SOURDEL-THOMINE, J. (1986): "Kitābāt", Encyclopédie de I'Islam. Nouvelle édition. V. pp. 208-2I3.

STERN, H. (1976): Les mosaïques de la Grande Mosquée de Cordoue. Madrider Forschungen, I I. Berlín.

TEMBOURY ALVAREZ, J. (1933): "Los descubrimientos de Gibralfaro", Archivo Español de Arte y Arqueología. 25. pp. 53-54.

\section{RESUMEN}

La finalidad de este trabajo es ofrecer una visión general y actualizada de la epigrafía andalusí, prestando especial atención a las principales etapas de la evolución de los signos gráficos. El volumen de información disponible permite plantear una valoración de conjunto de la epigrafía árabe de al-Andalus, aunque sea provisional para algunas zonas y periodos cronológicos concretos.

PALABRAS CLAVE: al-Andalus, epigrafía, cúfico, cursiva, evolución signos gráficos.
TERRASSE, H. ( 1932): L'art hispano-moresque des origines au XIII siècle. París.

TORRES BALBAS, L. (1926): "Paseos por la Alhambra. Una necrópolis nazarí: la rauda", Archivo Español de Arte y Arqueología. 2. pp. 216-285.

TORRES BALBAS, L. (1934a): " Monteagudo y El CastiIlejo en la vega de Murcia", Al-Andalus. II. pp. 366-372.

TORRES BALBAS, L. (1934b): "Paseos arqueológicos por la España musulmana", Boletín del Museo Provincial de Bellas Artes de Murcia. XI-XII. pp. I-6.

TORRES BALBAS, L. (1944): "La acrópolis musulmana de Ronda", Al-Andalus. IX. pp. 449-48I.

TORRES BALBAS, L. (1945): "El barrio de casas de la Alcazaba malagueña", Al-Andalus. X. pp. 396-409.

TORRES BALBAS, L. (1949): Arte almohade. Arte nazarí. Arte mudéjar. Ars Hispaniae. IV. Madrid.

TORRES BALBAS, L. (1957a): "Cementerios hispanomusulmanes", Al-Andalus. XXII. pp. |31-191.

TORRES BALBAS, L. (1957b): "Almería islámica", Al-Andalus. XXII. pp. 4II-462

TORRES BALBAS, L. (1958): "Játiva y los restos del palacio de Pinohermoso", Al-Andalus. XXIII. pp. I43-I7I.

TORRES BALBAS, L. (1960): "La primera versión del epígrafe fundacional de la mezquita de lbn 'Adabbas de Sevilla", Al-Andalus. XXV. pp. 219-221.

VALLEJO TRIANO, A. (1987): "El baño próximo al salón de 'Abd al-Rahmān III", Cuadernos de Madinat al-Zahrā'. l. pp. $|4|-\mid 52$.

VALLEJO TRIANO, A. (1992): "Madīnat al-Zahrā': el triunfo del Estado Islámico", J. D. Dodds (ed.): Al-Andalus. Las artes islámicas en España. Madrid, pp. 27-39.

VIVES Y ESCUDERO, A. ( I 893): Monedas de las dinastías arábigo-españolas. Madrid.

ZBISS, S.-M. (1977): Nouvelles inscriptions arabes de Tunisie. Túnez.

\section{RÉSUMÉ}

Le but de ce travail est d'offrir une vision générale de l'épigraphie andalousi. Nous avons choisi d'axer le travail sur les étapes les plus marquantes de l'évolution des tracés de la graphie. Le volume d'informations disponibles nous permet bien d'envisager une évaluation d'ensemble de l'épigraphie arabe d'al-Andalus, même si elle doit être provisionnelle pour certaines zones et certaines périodes chronologiques 


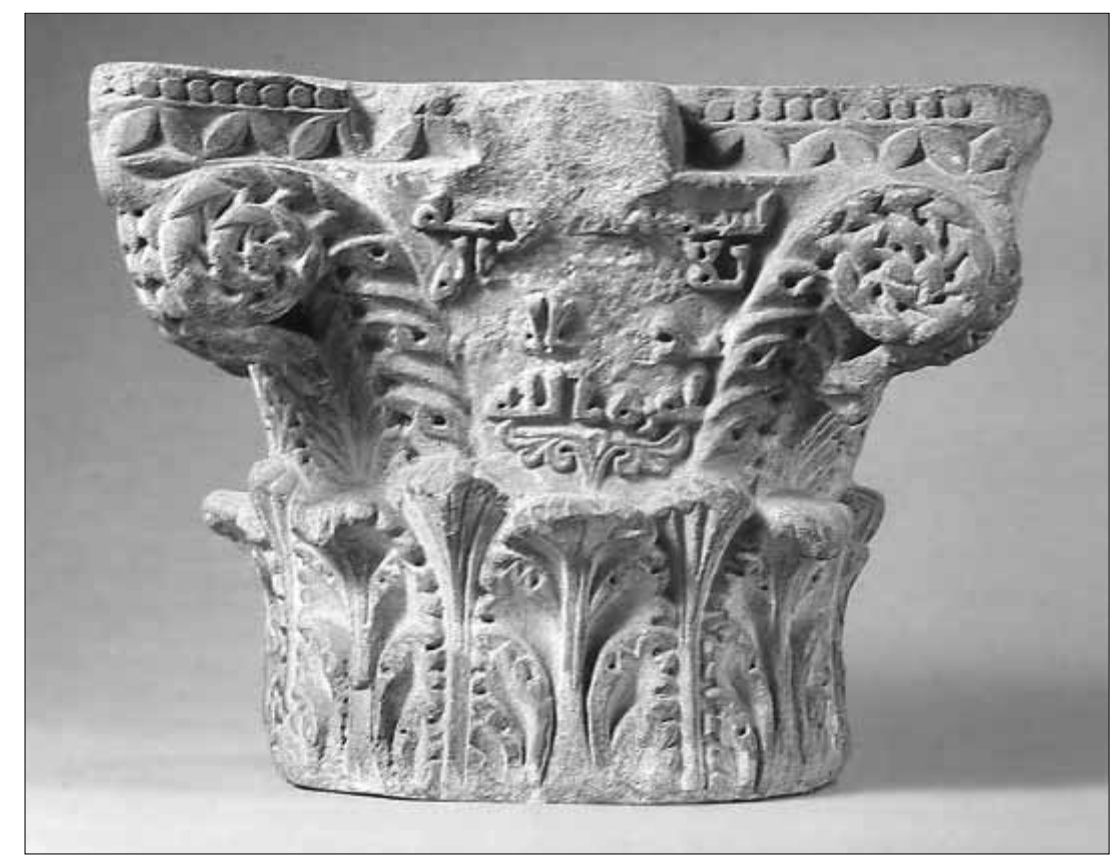

Fig. I. Capitel de 'Abd al- Rahmān II, posiblemente para la primera ampliación de la mezquita de Córdoba. Cúfico arcaico.

Fig. 2. Estela funeraria $(239 \mathrm{H}$./ 854 J.C.). Museo de Málaga. Cúfico arcaico.

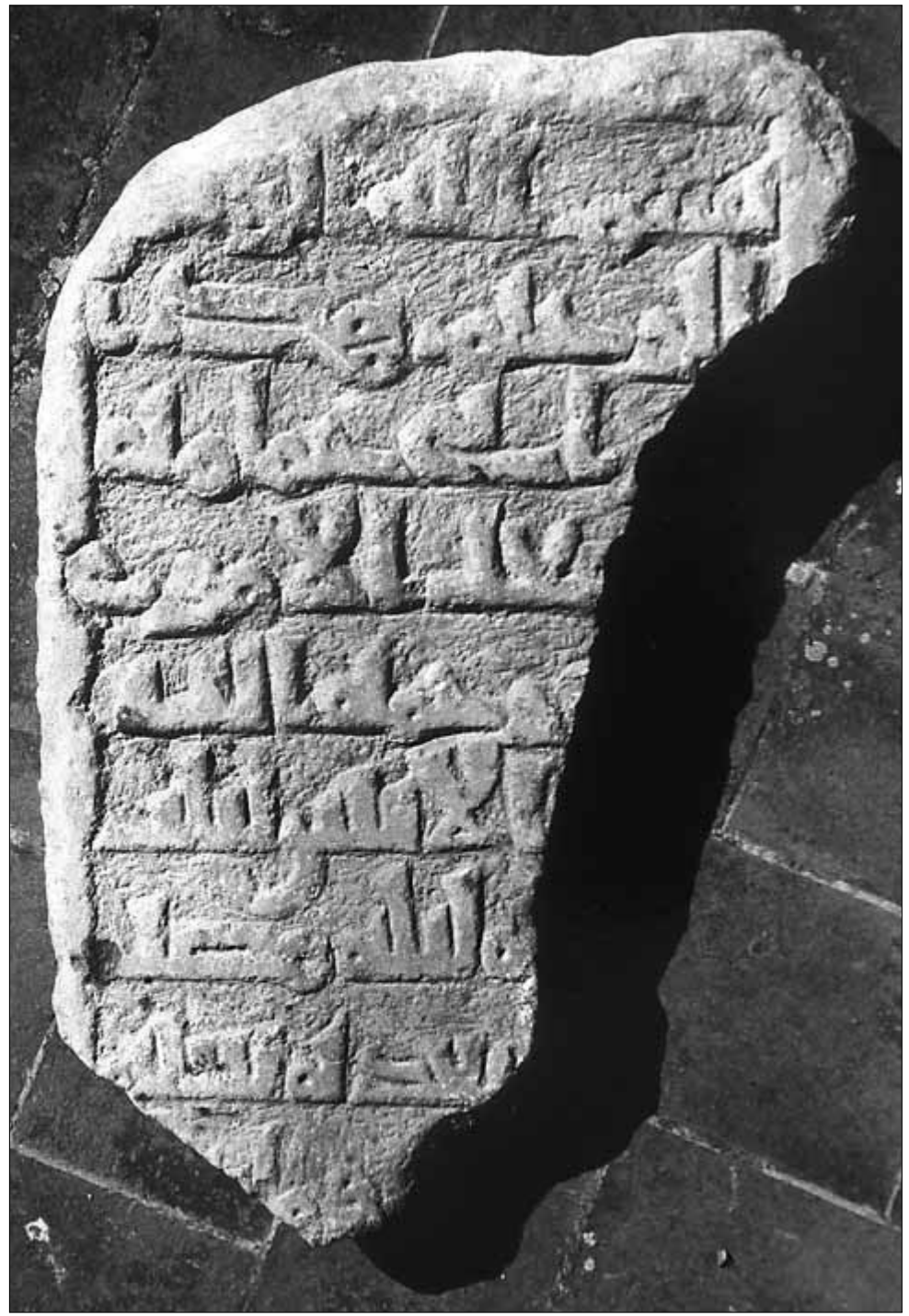




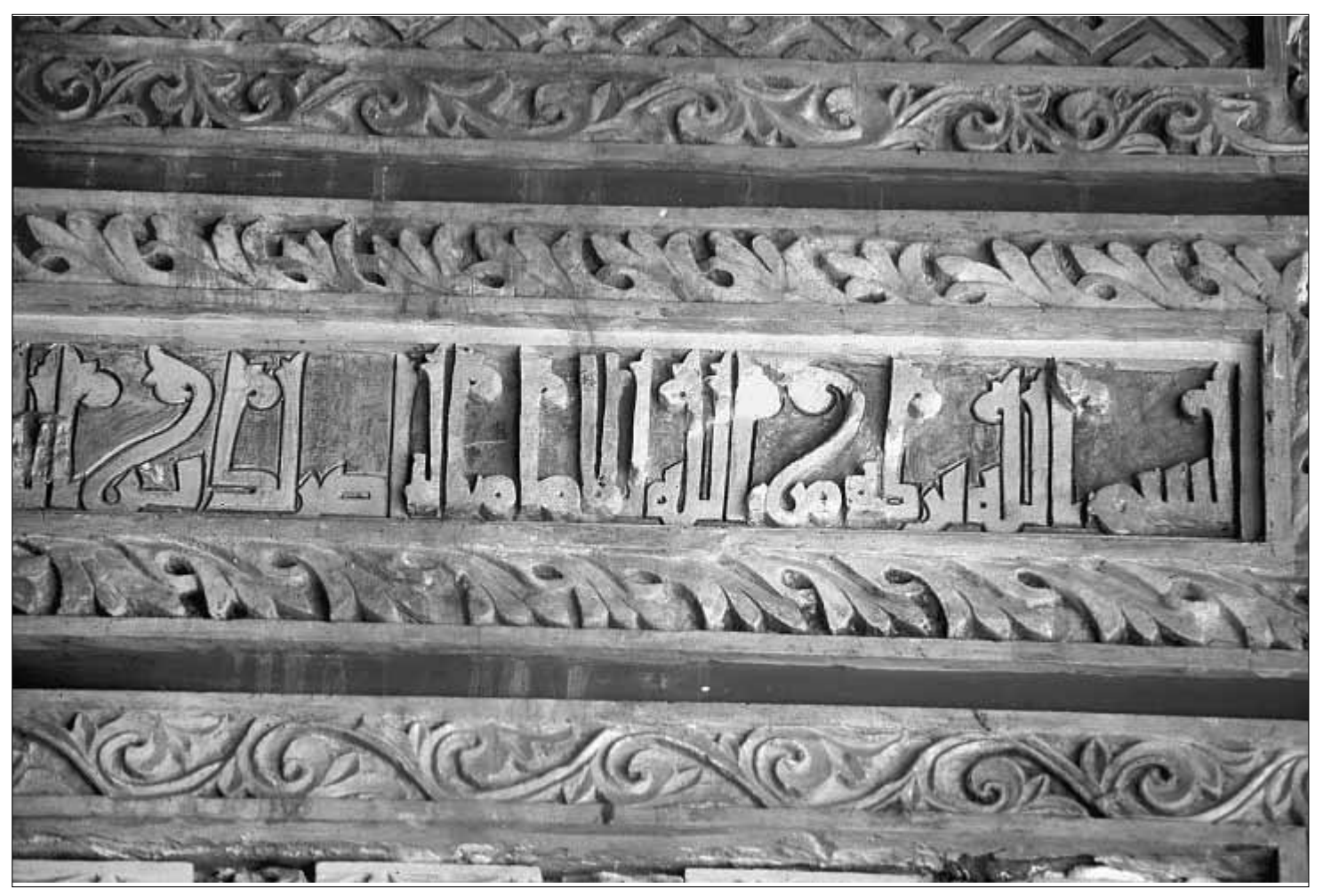

Fig. 3. Banda epigráfica de la arcada de acceso al salón de 'Abd al- Raḥmān III, en Madinat al-zahrā' (345 H.1956-7 J.C.). Cúfico florido.

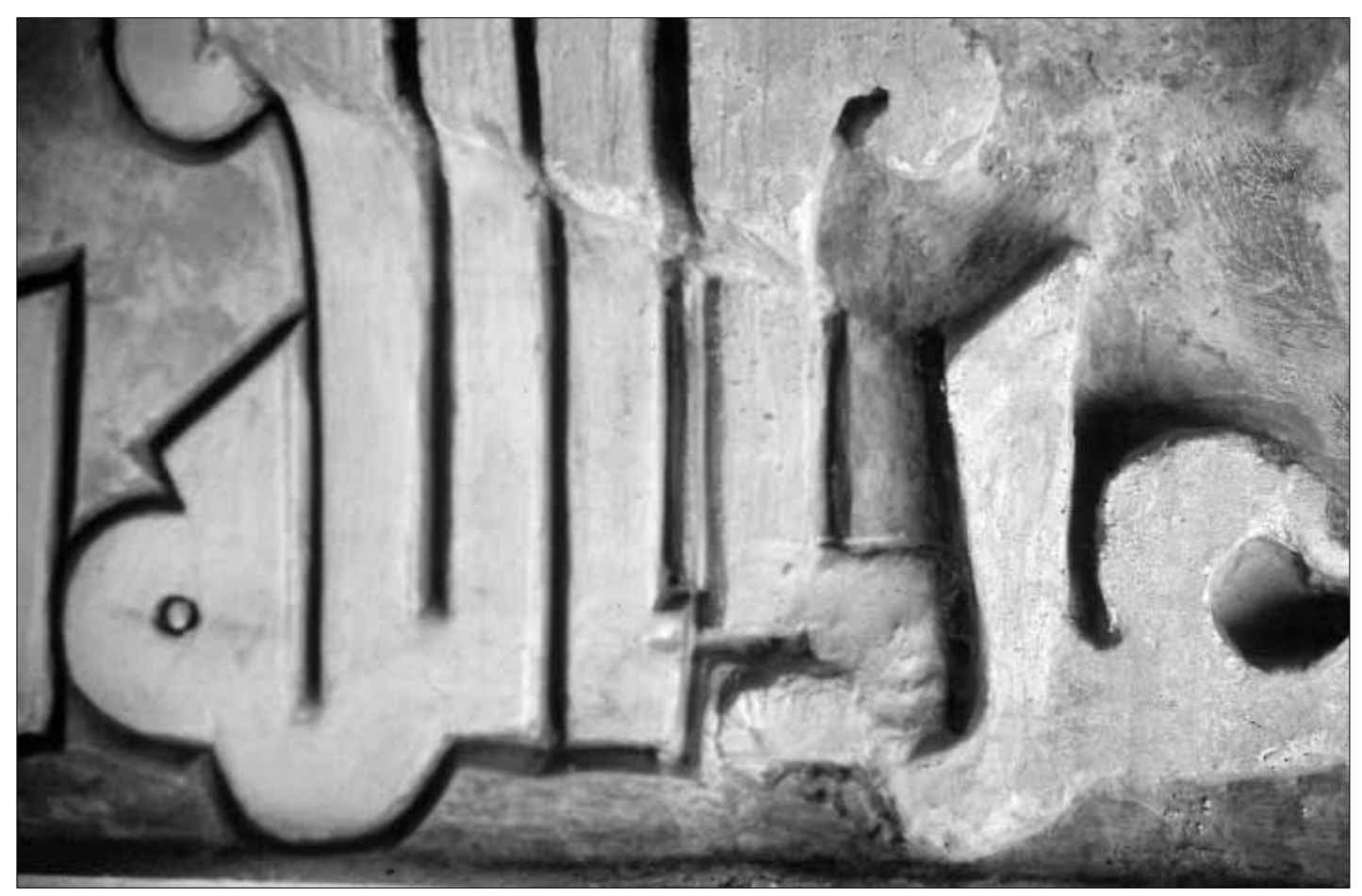

Fig. 4. Detalle del epígrafe anterior: nexo curvo entre los grafemas $2 m$ y $4 f$. 
Fig. 5. Detalle del epígrafe del interior del Mihrāb de la Mezquita de Córdoba (354 H.1965 J.C.). Cúfico simple
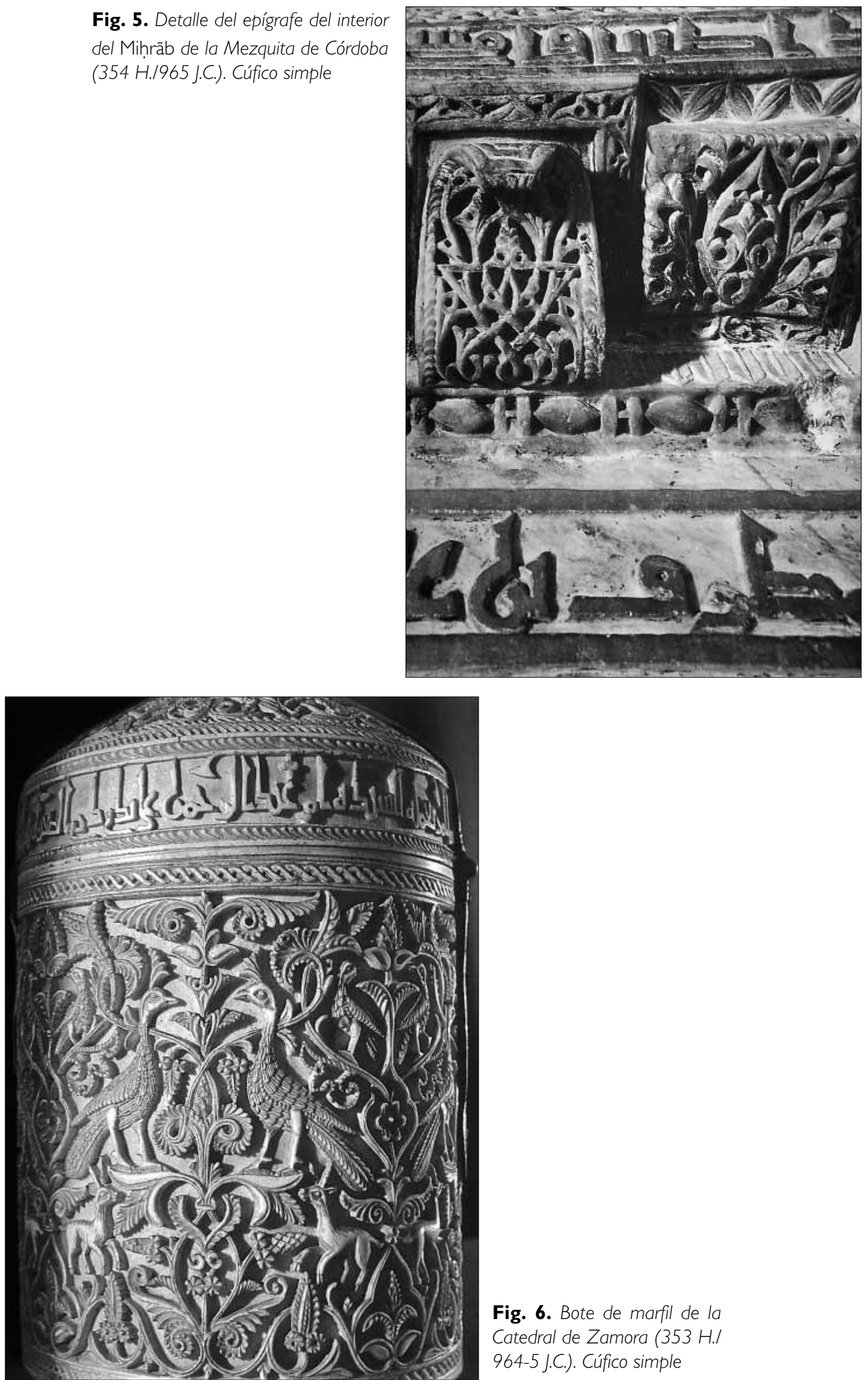

Fig. 6. Bote de marfil de la

Catedral de Zamora (353 H.l

964-5 J.C.). Cúfico simple 


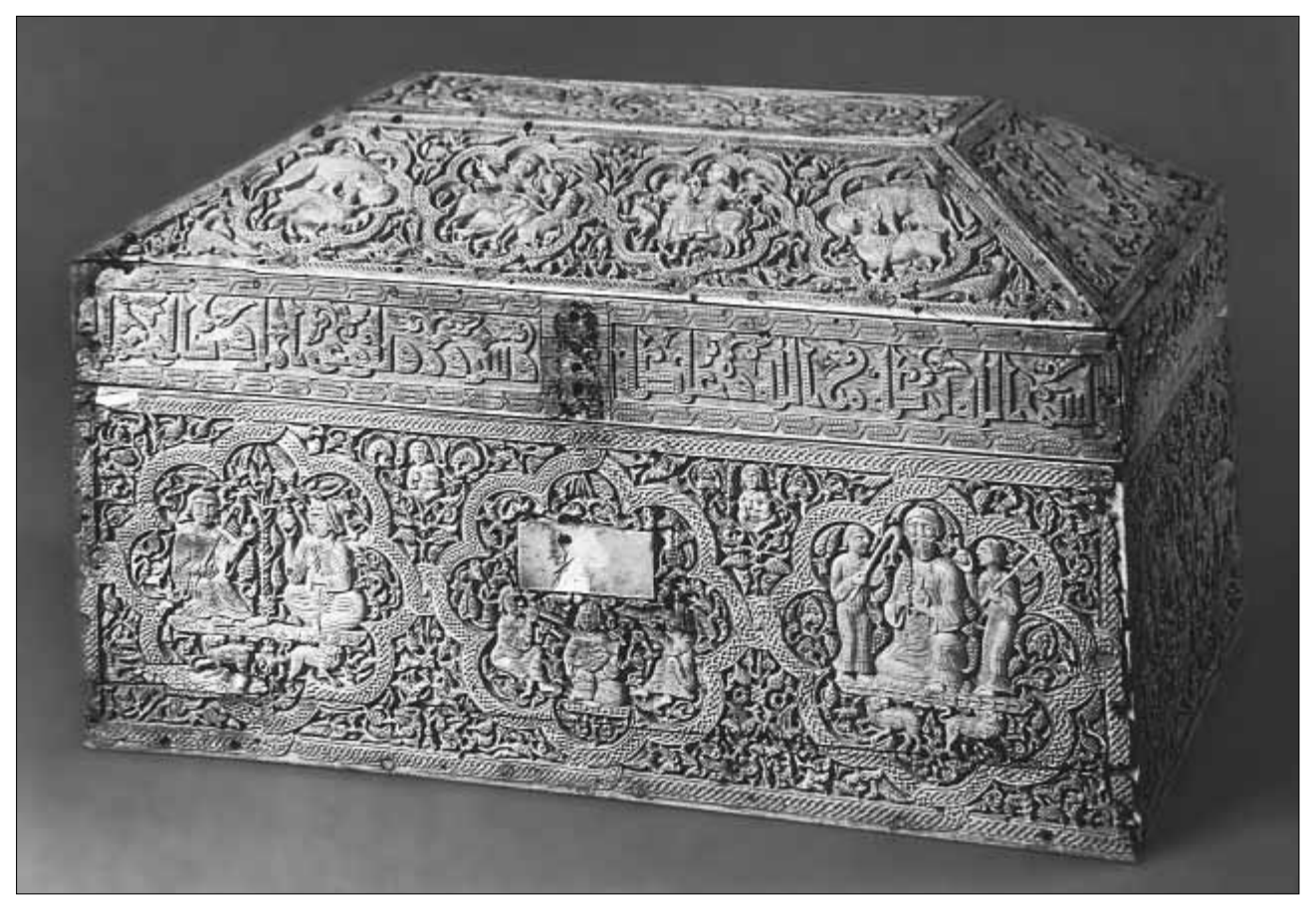

Fig. 7. Arqueta de Leyre (395 H./l004-5 J.C. ). Cúfico de diseño simple con algunos remates florales.

Fig. 8. Elementos decorativos y bandas epigráficas del Miḥrāb de la Aljafería de Zaragoza

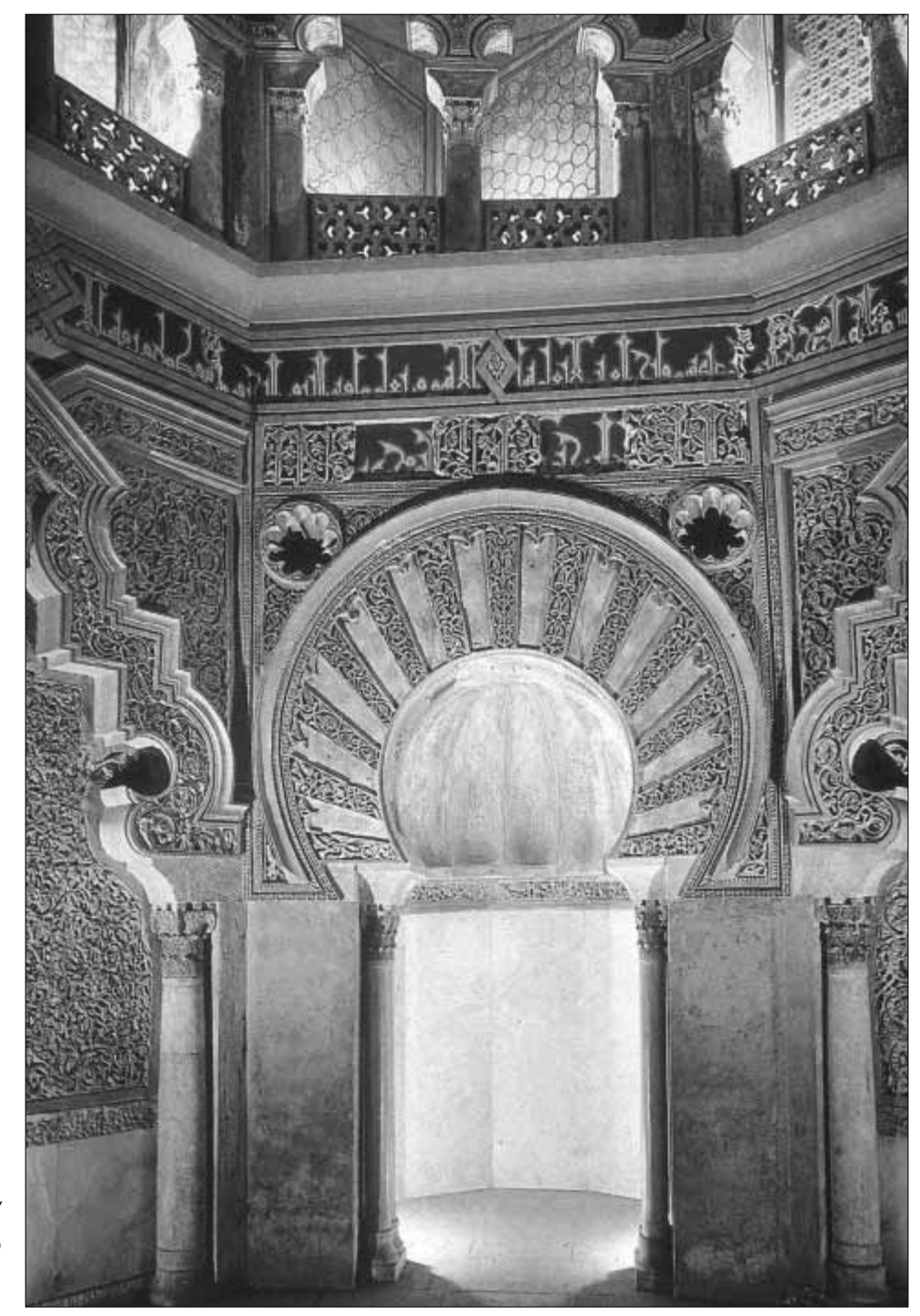



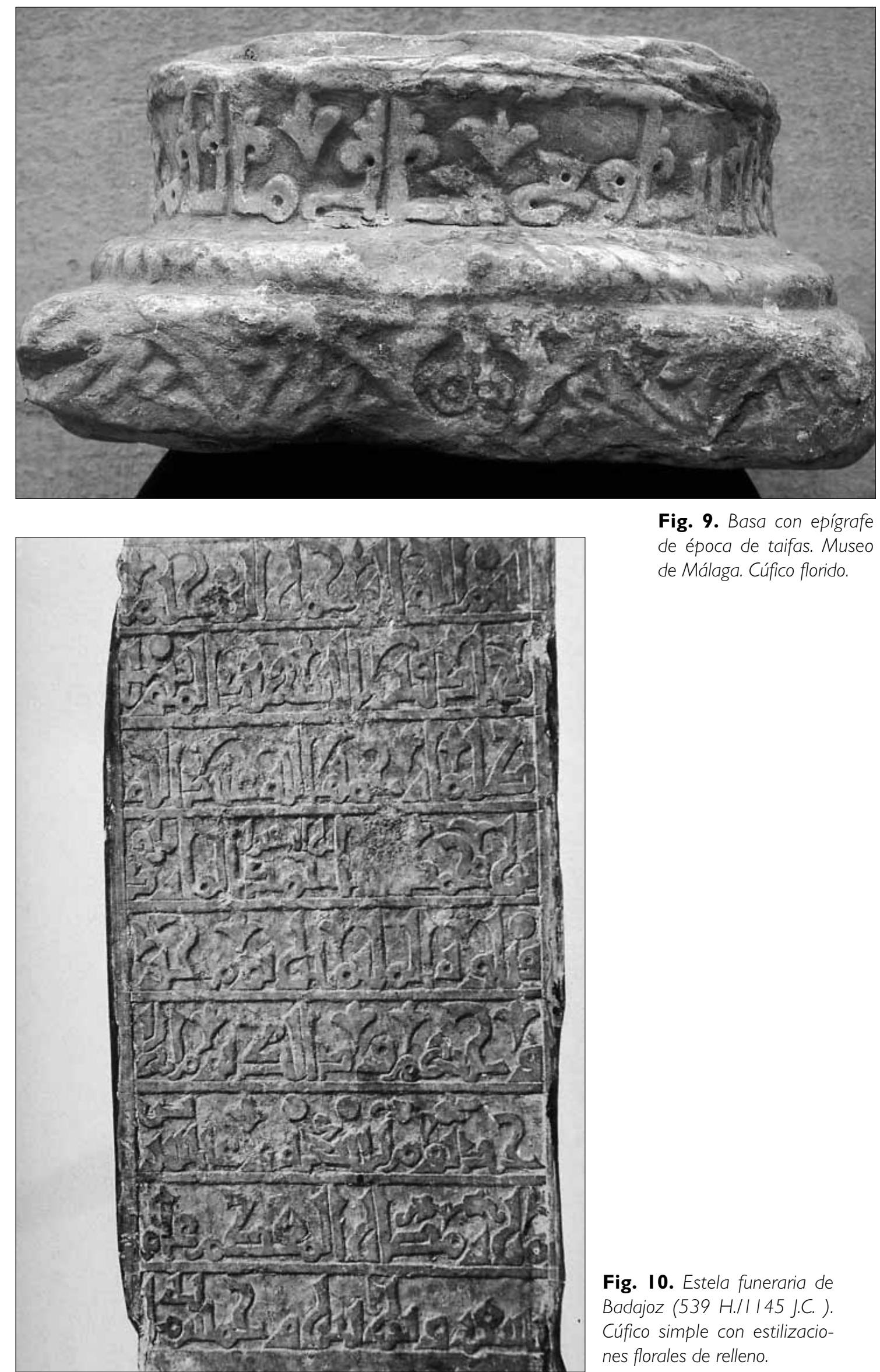

Fig. 9. Basa con epígrafe de época de taifas. Museo de Málaga. Cúfico florido.

Fig. I0. Estela funeraria de Badajoz (539 H./ I I 45 I.C.). Cúfico simple con estilizaciones florales de relleno. 

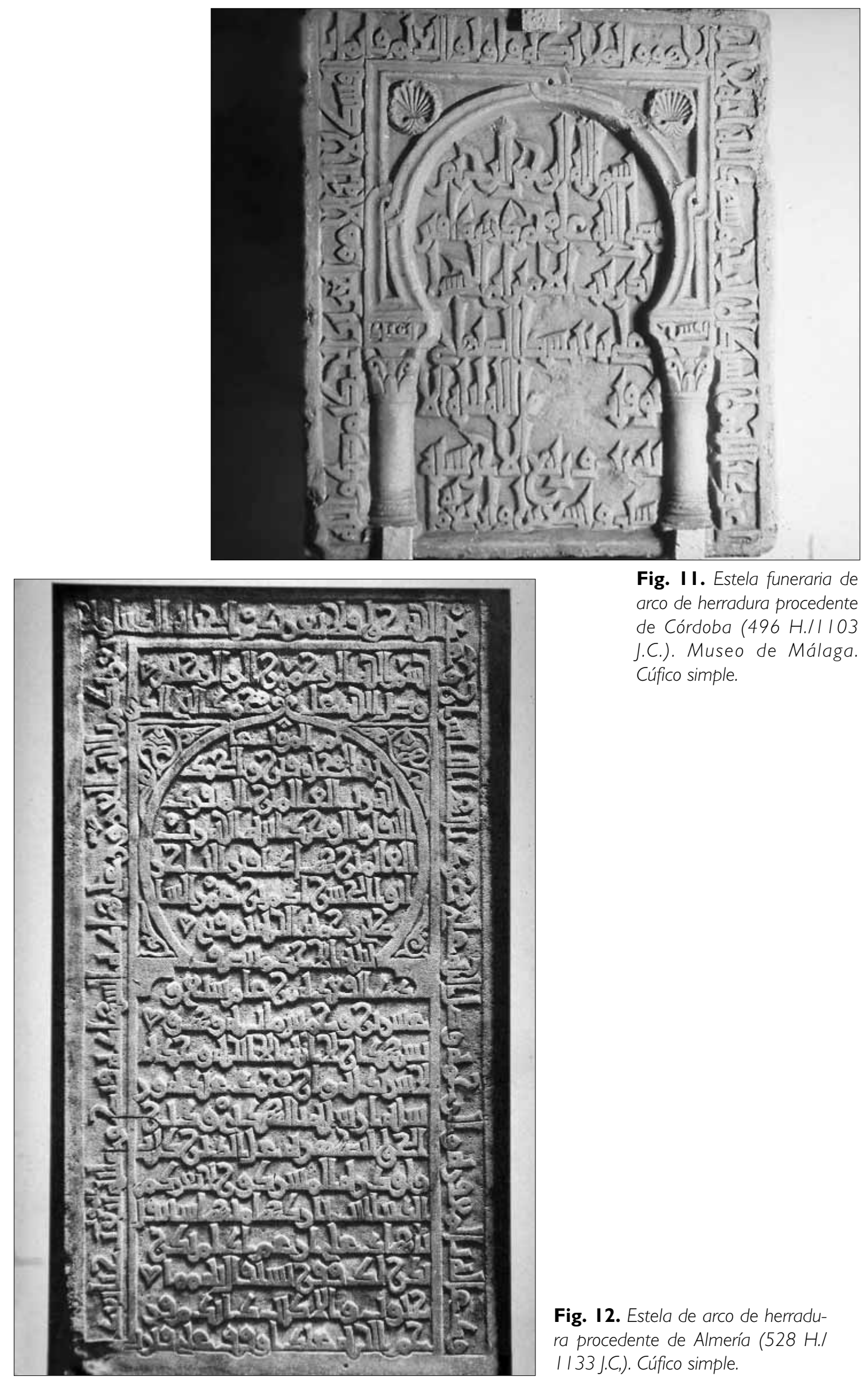

Fig. I I. Estela funeraria de arco de herradura procedente de Córdoba (496 H./l lo3 J.C.). Museo de Málaga. Cúfico simple.

Fig. I 2. Estela de arco de herradura procedente de Almería (528 H.l I 33 J.C,). Cúfico simple. 


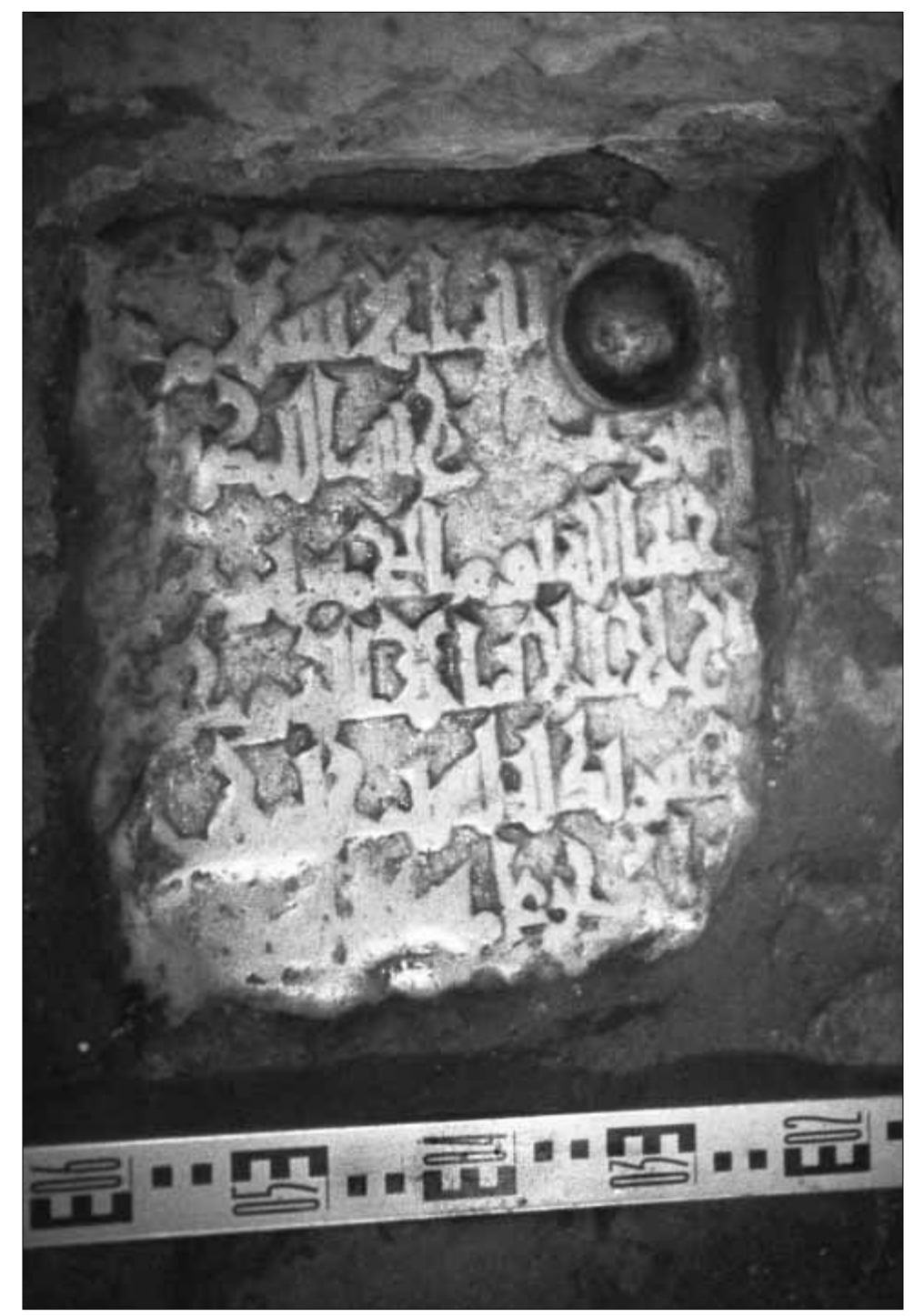

Fig. I3. Estela funeraria

aparecida en las excavaciones arqueológicas realizadas en la Iglesia de la Magdalena en Córdoba ( ${ }^{a}$ mitad del siglo XII). Cúfico simple.

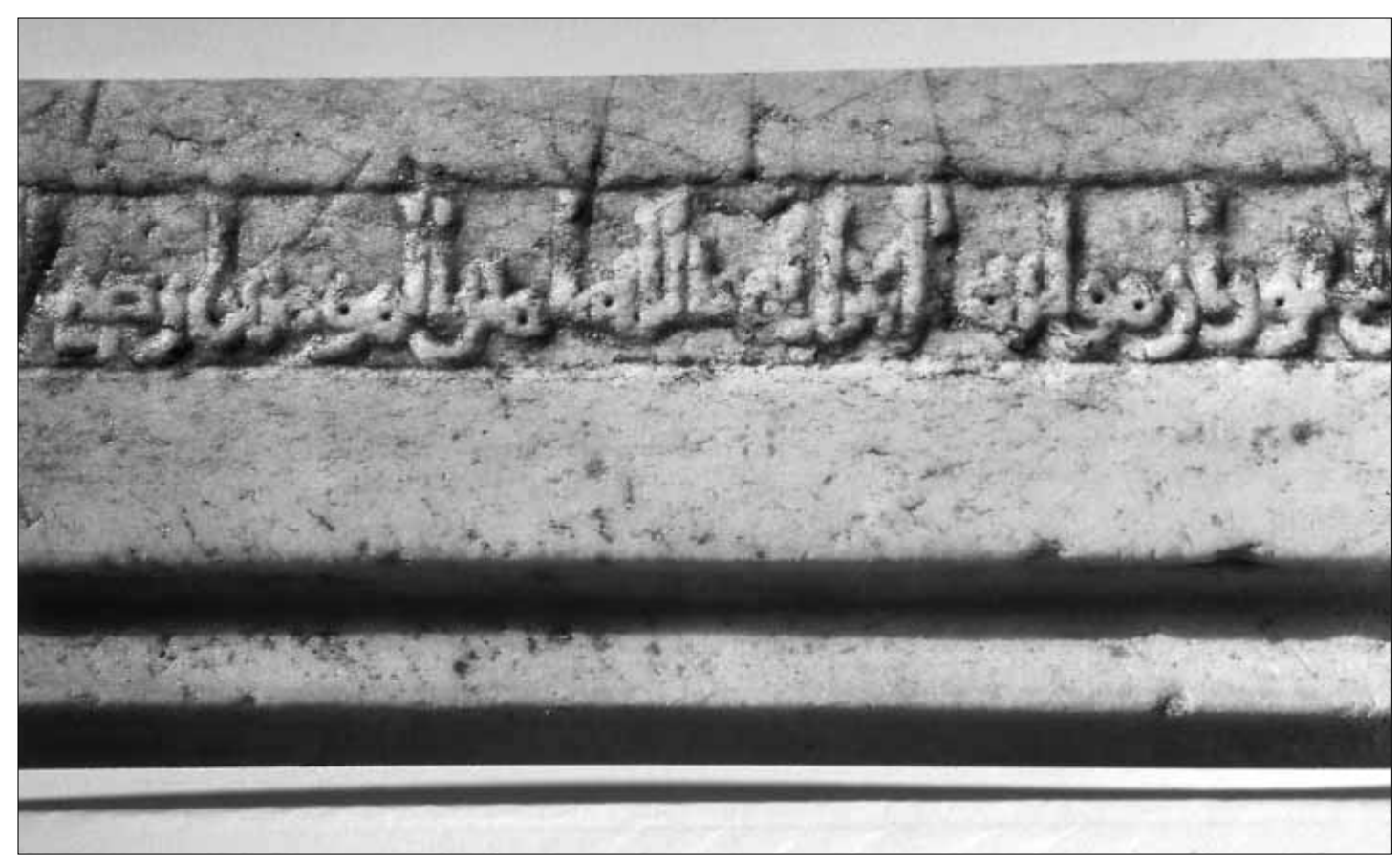




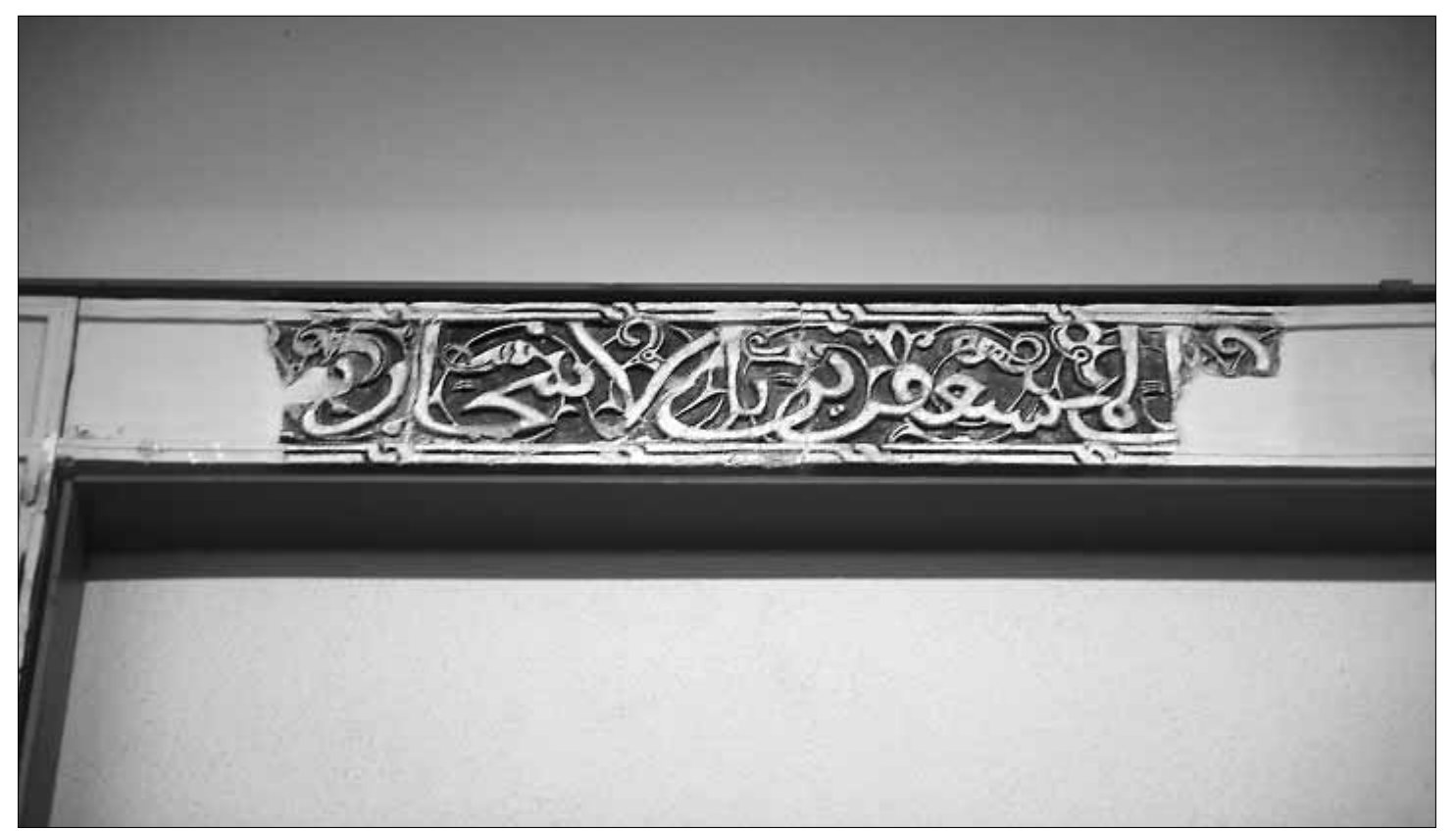

Fig. I5. Detalle de una banda epigráfica en estuco del Museo de Murcia (siglo XII-XIII). Grafía cursiva.

Fig. 16. Elementos decorativos del Mihrāb de la Mezquita de Tinmal (549 H./l I 54 J.C. ), en Marruecos.

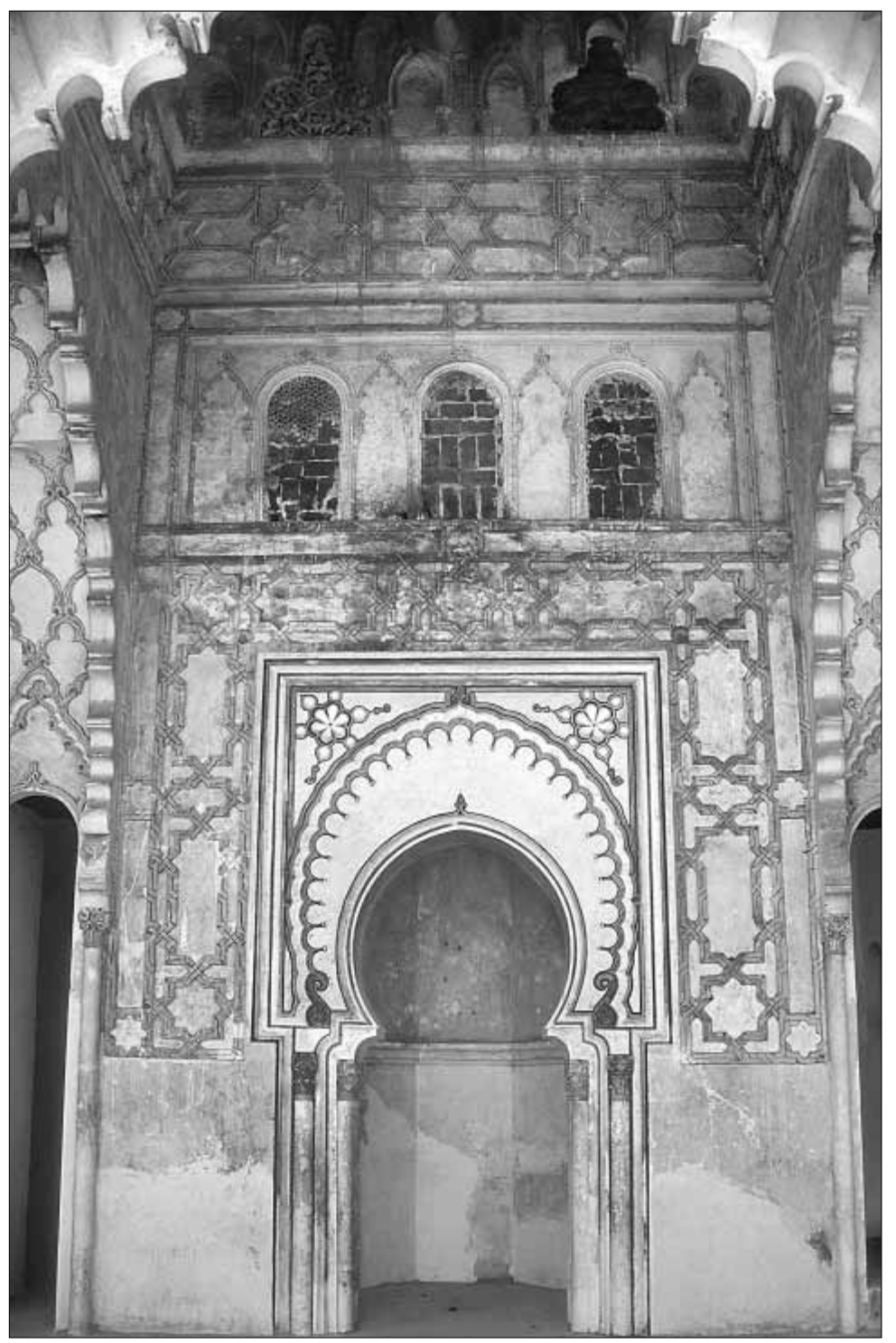




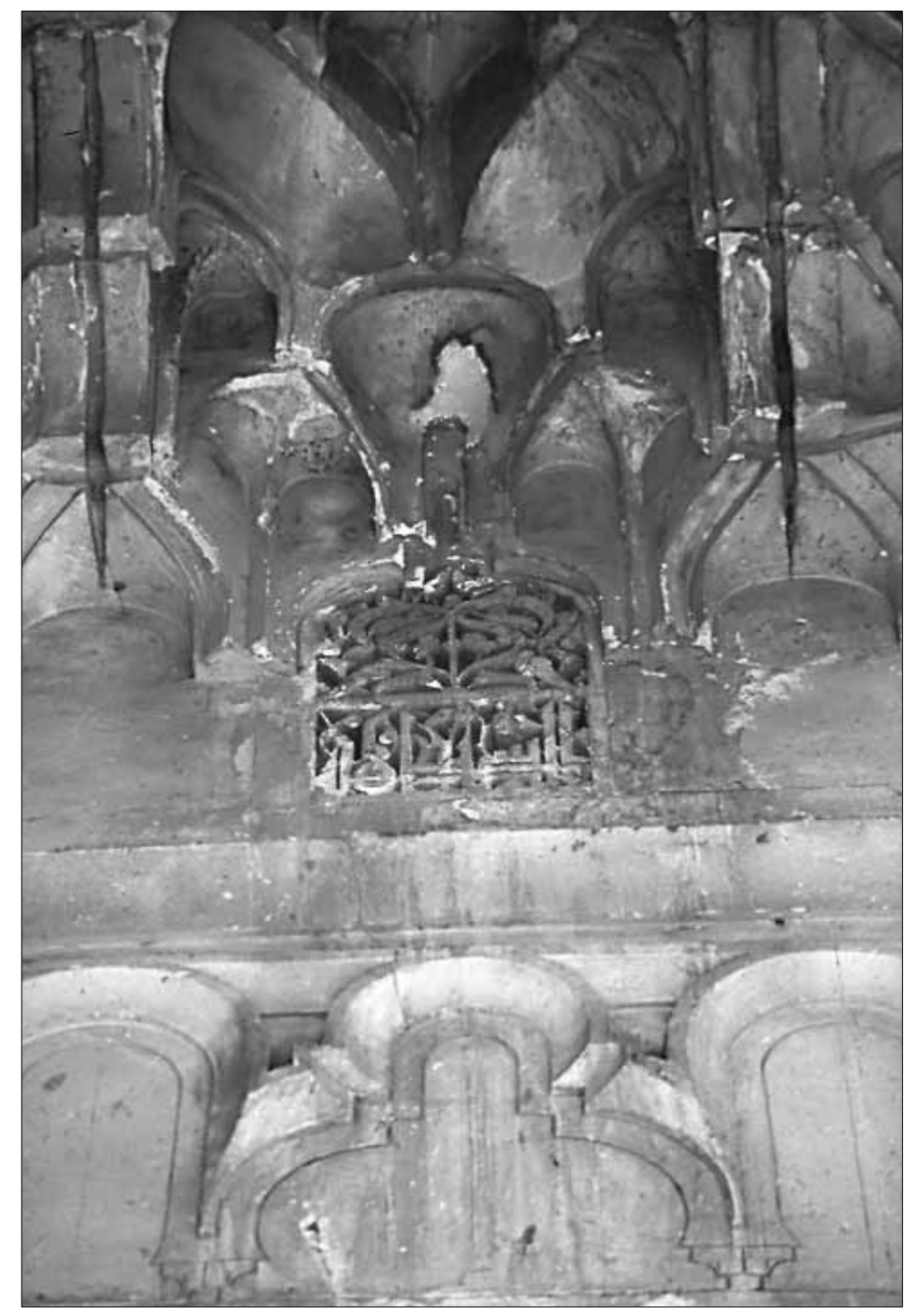

Fig. I 7. "Motivo tipo" de la cúpula de la antesala al Miḥrāb de Tinmal. Grafía cúfica

Fig. I 8. "Motivo tipo" y banda epigráfica de la puerta de la qasbah de los Udaïa ( I 194 J.C.) en Rabat. Cúfico simple con estilizaciones vegetales de relleno.

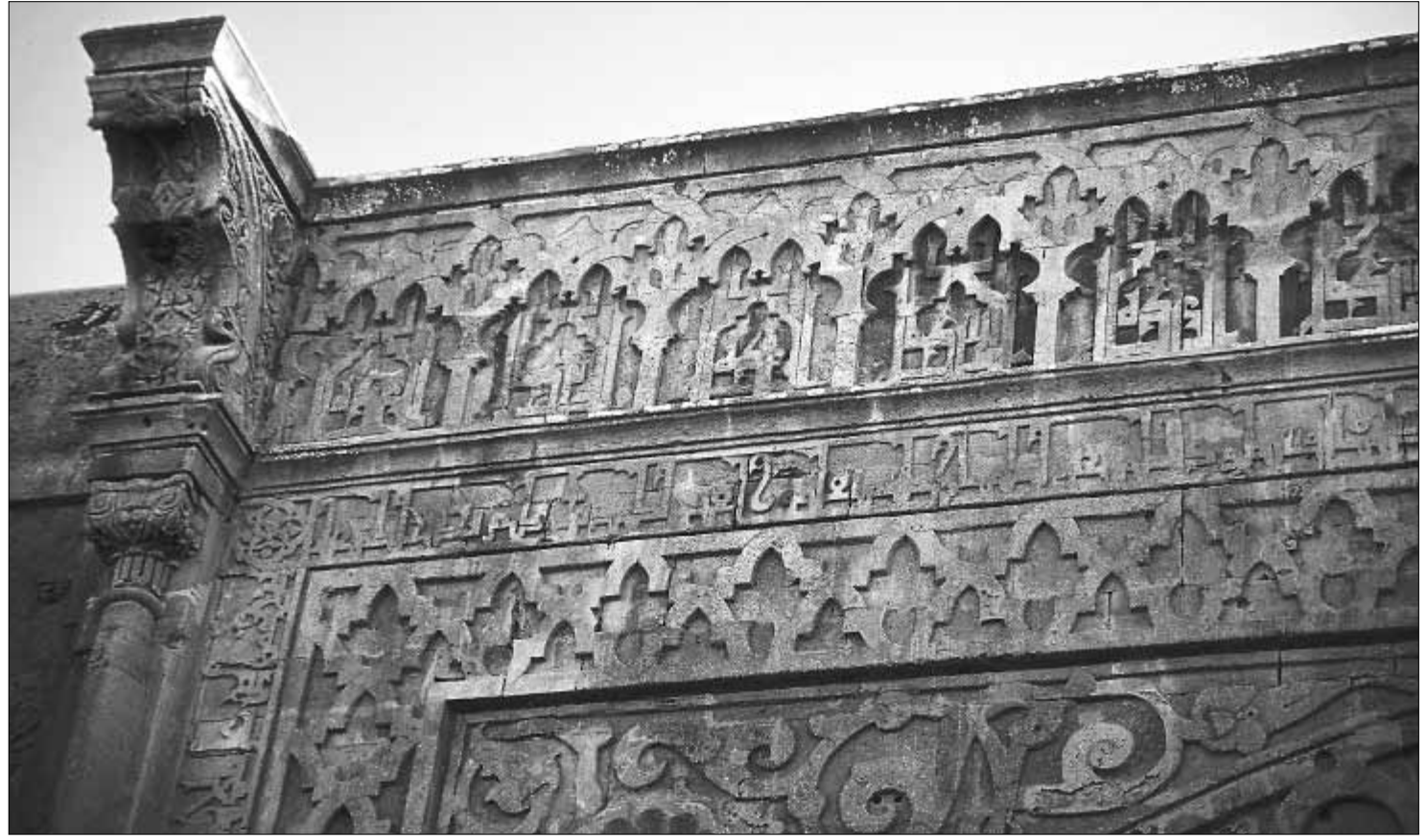




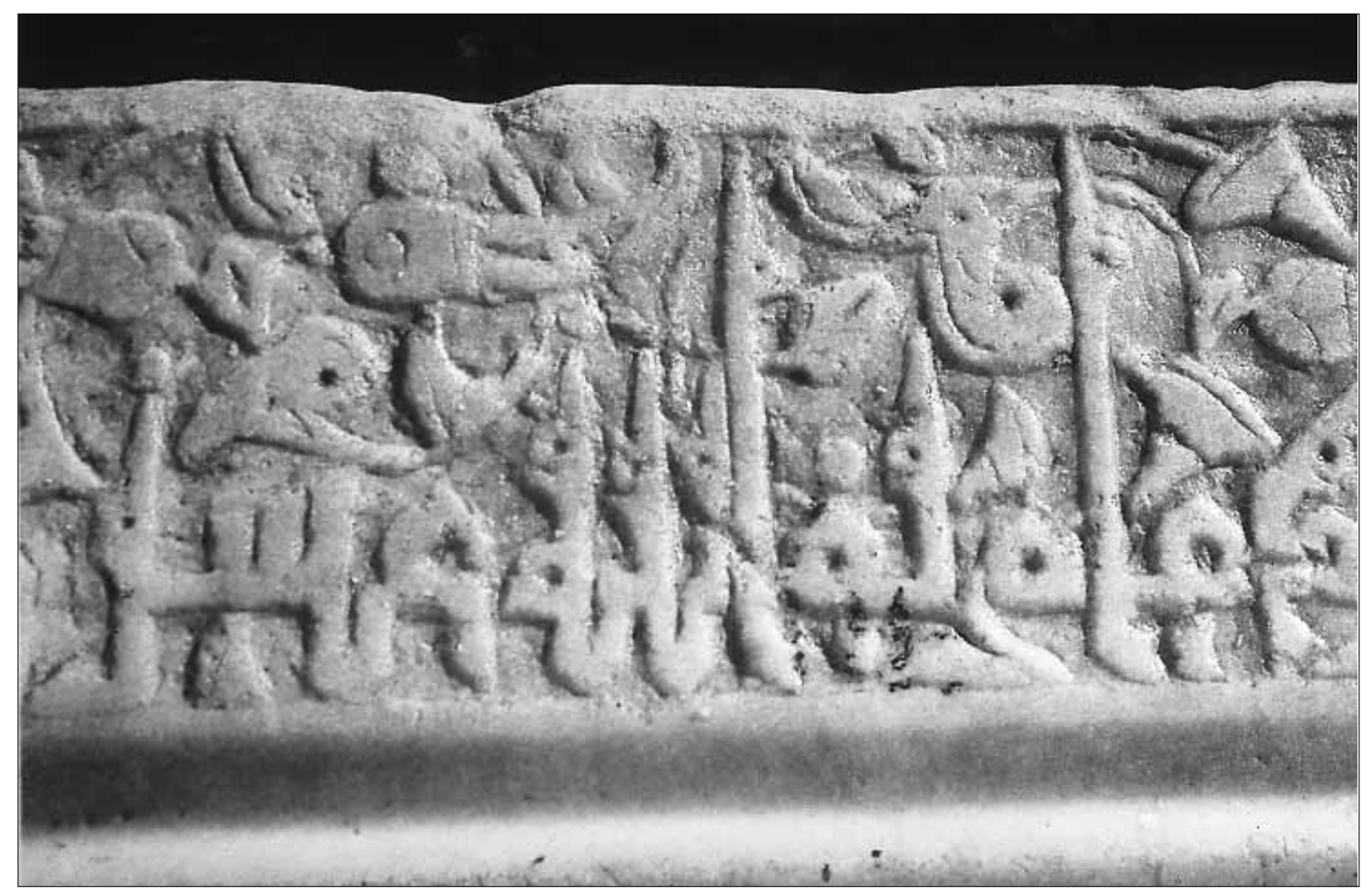

Fig. 19. Detalle de la mqābriyya almohade (6 / 8 H./l 22 I J.C.) del Museo de Málaga. Grafía cúfica con abundante decoración vegetal de relleno.

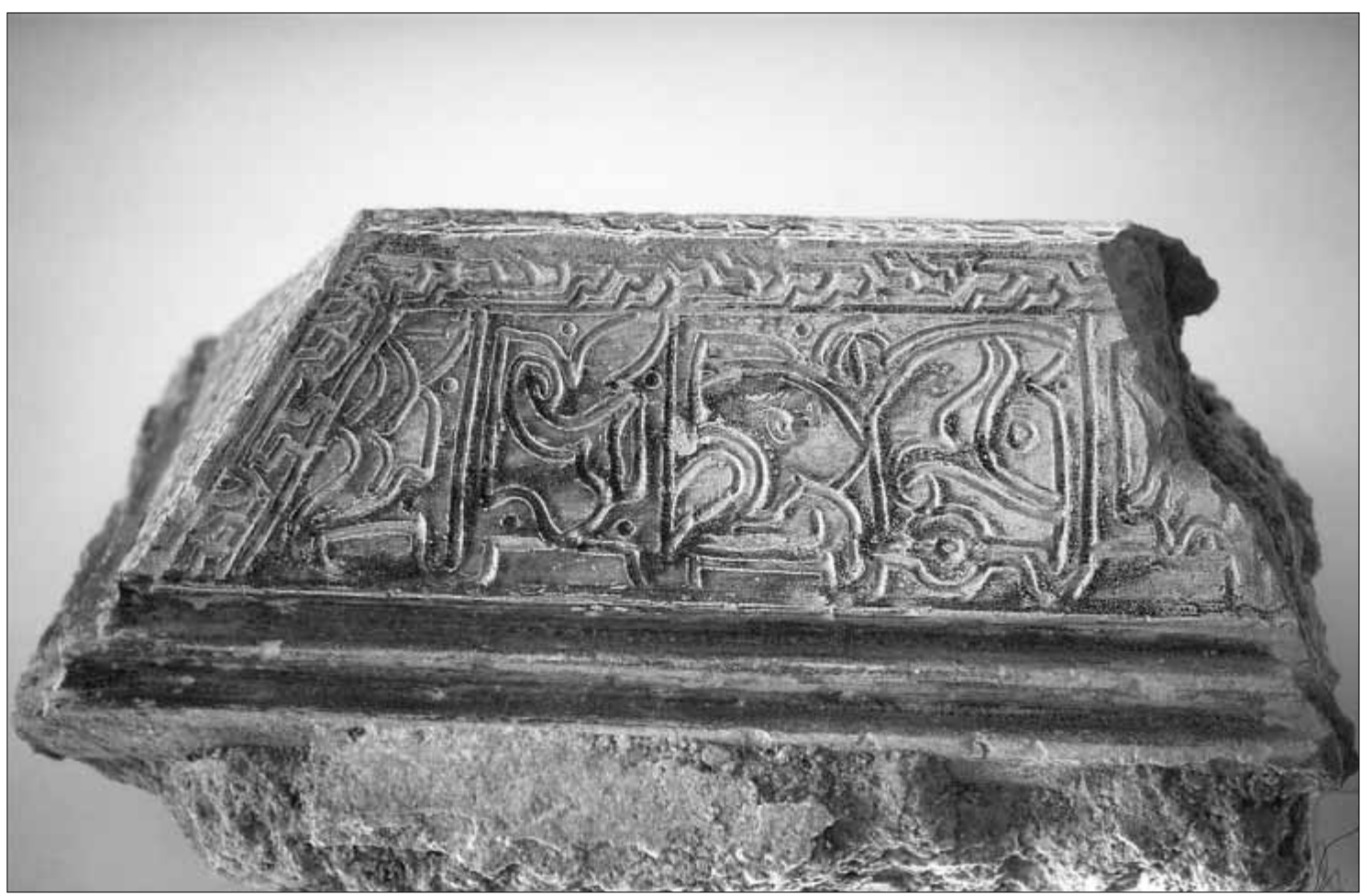

Fig. 20. fragmento de mqābriyya vidriada en verde, aparecida en Málaga. Cúfico Almohade. 


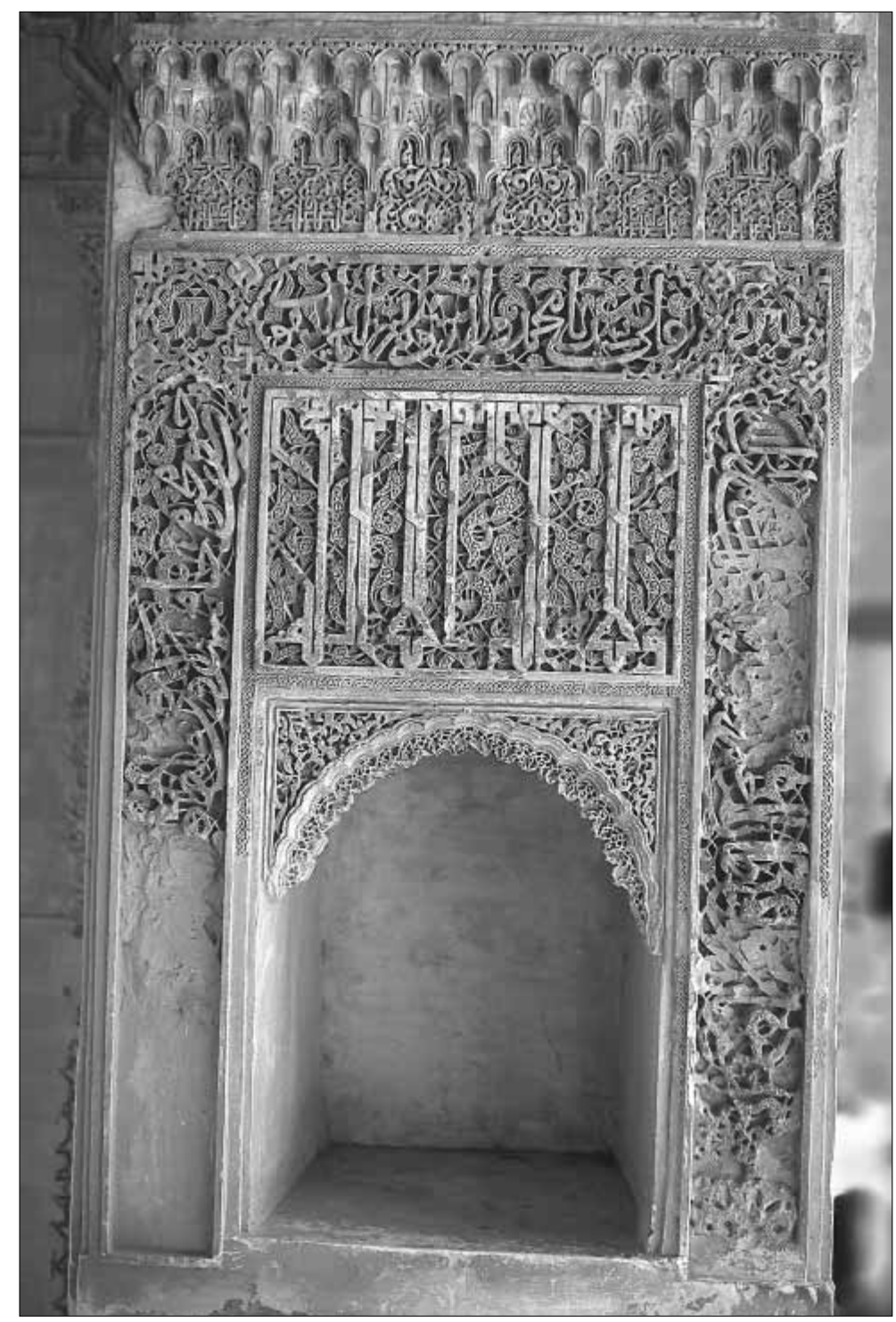

Fig. 2 I. Taq̄a del Partal en la Alhambra. "Motivos tipo", grafía cúfica y cursiva nazaríes.

Fig. 22. Fragmento de estela funeraria de época nazarí, aparecida recientemente en Málaga. Epitafio de un šayj al guzāt meriní. Grafía cursiva.

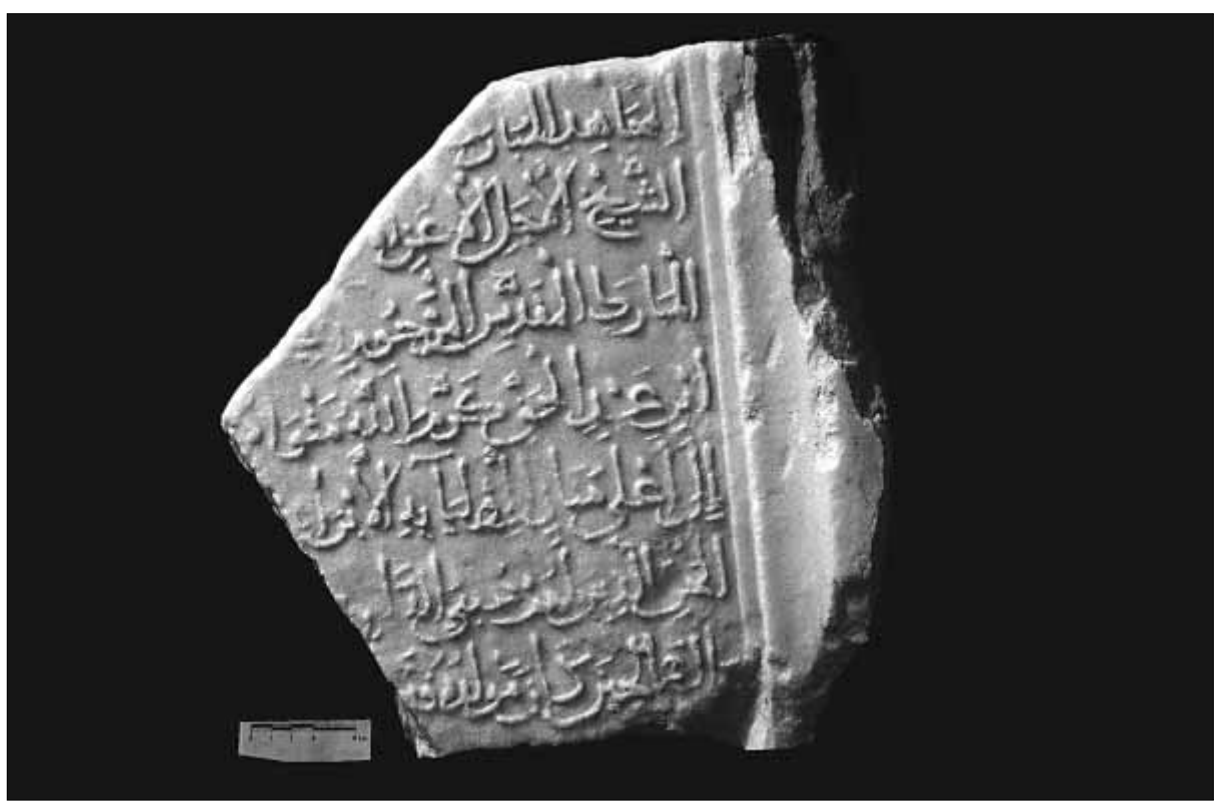




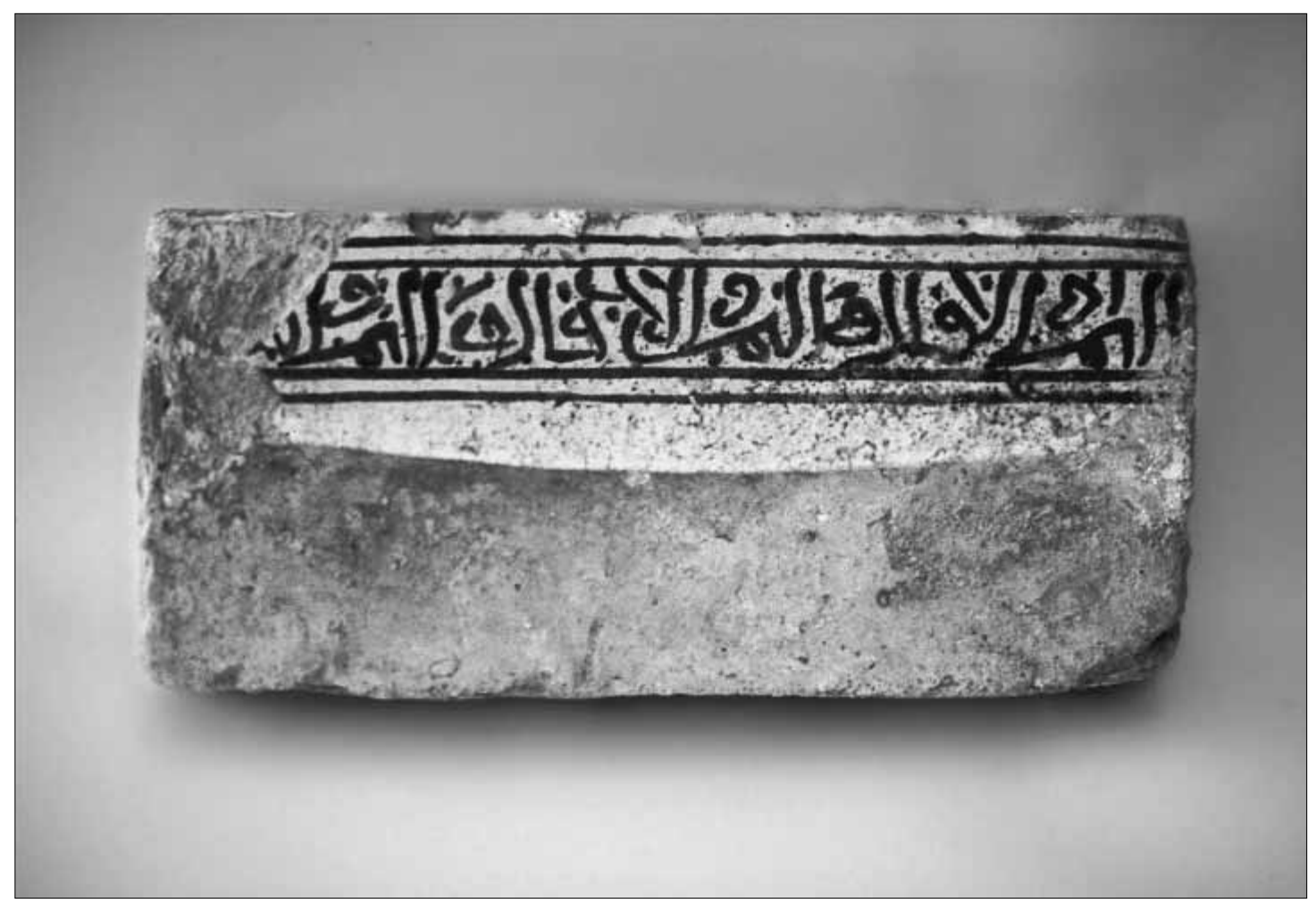

Fig. 23. Ladrillo funerario malagueño de época nazarí. Grafía cursiva.

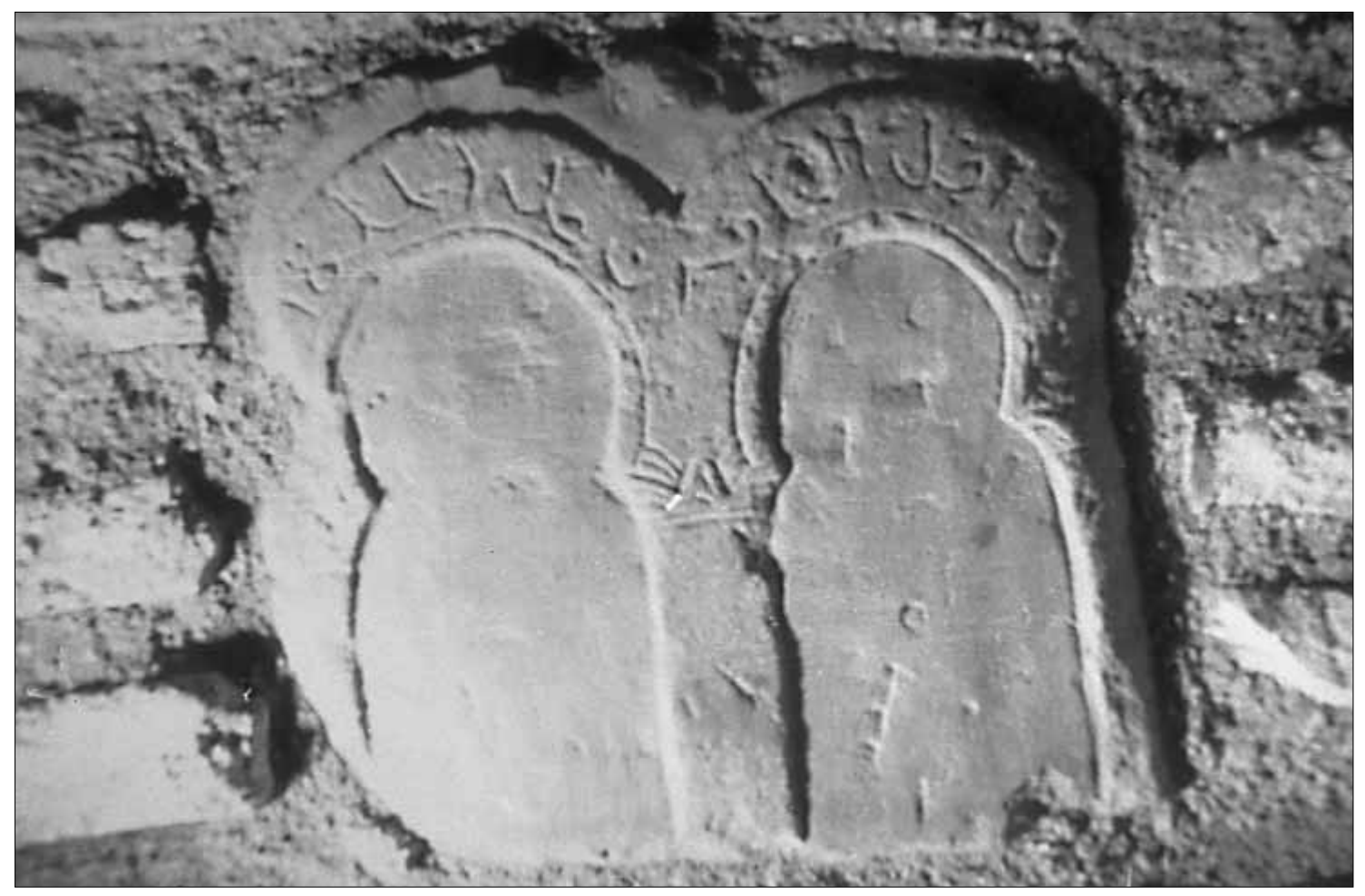

Fig. 24. Estela funeraria de arenisca de Ronda. Grafia cursiva. 